\title{
Optimal design of hybrid energy systems incorporating stochastic renewable resources fluctuations
}

\author{
Oluwamayowa O. Amusat ${ }^{\mathrm{a}}$, Paul R. Shearing ${ }^{\mathrm{b}}$, Eric S. Fraga ${ }^{\mathrm{a}, *}$ \\ ${ }^{a}$ Centre for Process Systems Engineering, Department of Chemical Engineering, University College London, Torrington \\ Place, London WC1E 7JE, United Kingdom \\ ${ }^{b}$ Electrochemical Innovation Lab, Department of Chemical Engineering, University College London, Torrington Place, \\ London WC1E 7JE, United Kingdom
}

\begin{abstract}
The potential impacts of variability and intermittency in renewable resources on the design of stand-alone renewables-based energy systems incorporating storage are addressed at the design stage. The framework developed accounts for climate-based variability by considering different stochastically-generated renewable input scenarios in the evaluation of system reliability. Operational constraints which control the availability and discharge of storage technologies based on previous storage states and technology start-up times are incorporated into the energy system model to account for the intermittent power output from renewables. A cost-reliability bi-criteria sizing problem is solved for two cases of a remote Canadian mine to demonstrate that intermittency in generation can influence technology choices, system configuration and system operation. Approximations to the non-dominated fronts are generated with NSGA-II, and the operating characteristics of the maximum-reliability designs generated in the cases are investigated. The methodology provides the decision maker with information about a number of operable designs and an understanding of the performance risks associated with the selection of any given design.

Keywords: Hybrid energy systems design; intermittency; multi-objective optimization; reliability; renewables variability.
\end{abstract}

\section{Introduction}

Industrialization and rapid population growth have led to a steady rise in the demand for energy. The global energy demand is expected to rise by between $30 \%$ and $40 \%$ by 2040 [31, 51]. The industrial sector is the chief consumer of energy, demanding $42.5 \%$ of the world's electricity generation in 2014, along with significant

\footnotetext{
${ }^{*}$ Corresponding author

Email addresses: oluwamayowa.amusat.13@ucl.ac.uk (Oluwamayowa O. Amusat), p.shearing@ucl.ac.uk (Paul R. Shearing), e.fraga@ucl.ac.uk (Eric S. Fraga)
} 
quantities of coal, natural gas and oil [30. The mining industry accounts for a significant portion of this energy demand. Mining operations involve several energy intensive processes such as drilling, excavation and blasting [53], and energy costs have been shown to represent between 15-21\% of the total cost of production in the mining industry [45, 67]. The rising demand for metals around the world, coupled with the depletion of readily accessible ore deposits, has led to mining operations moving to more remote locations where they often face significant energy problems since grid electricity is usually unavailable. Such mines typically resort to the use of diesel generators, leading to a substantial increase in the overall mining cost. The fuel is transported over large distances using trucks, raising safety concerns, and the of diesel generators also leads to significant greenhouse emissions, translating to high carbon footprints. These challenges, along with increased pressure from governments, have driven mining operations to seek alternative sources of energy.

Energy generation from renewables is considered to be the most promising solution to the mining industry's energy challenge [53]. Remotely located mines usually have good access to land and are often located in regions with extreme climatic conditions; making them ideal for renewable energy use. Operating mines entirely on renewable energy offers several advantages which are attractive to mine owners, some of which include: energy security over mine lifetime, reduction in operating (fuel, emissions and transportation) costs, lower environmental impact, and improvement of overall plant safety because of reduced need for transportation and storage of flammable compounds. Despite these advantages, the use of renewables-based energy systems as the primary energy sources in continuous processes has been limited due to the variable and intermittent nature of renewable resources. Energy storage integration is therefore critical if renewable generation is to achieve higher levels of penetration into the mining industry. Energy storage helps to address the variability and generation-demand imbalance challenges associated with renewables generation 8]. Storage options integrated with renewables need to be able to serve three main purposes in order provide smooth, uninterrupted power and maximize system efficiency and reliability: load shifting, standby reserve and power quality management [22]. The design of a standalone renewable energy system will involve the selection and sizing both renewable generation and energy storage technologies.

The challenge of accounting for renewables climate-based variability in energy systems design and sizing has been addressed by several researchers. Two major approaches have been used to account for the stochastic nature of renewables: probabilistic and time-series approaches. In the probabilistic approach, all the variables participating in the energy conversion process are modelled as random variables [62]. The performance of the energy system is assessed analytically by combining the probability distribution functions (PDFs) of the variables [13. Karaki et al. [34, Tina et al. [63], Khatod et al. [37] and Gooding et al. [26] applied the approach to PV-wind and PV-wind-diesel systems, with the approach recently extended by Paliwal et al. 
52] to PV-wind-battery systems. With the time-series (chronological) approach, the amount of renewable resource available at a given time is modelled as a single value which is considered typical for that time instant. The resource availability over the entire period is therefore represented by time series data. With this approach, climate-based variability is incorporated by considering multiple time-series data when evaluating the performance of any energy system. The chronological approach was demonstrated by Kaplani and Kaplanis [33] for PV-battery systems. More recently, Amusat et al. 4] applied this approach to systems integrating multiple thermal and electrical generation and storage technologies.

The intermittent nature of the wind resource has been accounted for in planning and sizing of energy systems integrating wind and diesel generation [11, 12, 37]. The works constrain the maximum fraction of the load which can be met directly from wind generation, forcing a significant portion of the base load to be met from dispatchable energy sources (diesel generators). Weisser and Garcia [68] recommend limiting the contribution of wind generation to the energy mix to about $30 \%$ to ensure energy system stability. Several works have also considered how energy storage could be used to increase the wind contribution to the energy mix [65, 15]. The incorporation of wind penetration limits is particularly applicable for wind integration into the energy grid where other non-renewable sources are readily available.

However, very little has been done to address the intermittency challenge in the sizing of standalone systems wholly dependent on renewables generation. For such systems, power fluctuations are a serious issue since diesel generation is unavailable. The lack of attention to this area has primarily been because most works on standalone energy systems design consider only battery storage [47, 1, 60, 64]: the instantaneous response times of batteries mean that the power fluctuations do not need to be considered separately during sizing. However, works in literature [29, 40] have suggested that it may be necessary to incorporate more than one storage type for systems which provide large amounts of energy in order to meet all the technical requirements for power system operations. With the incorporation of other storage options, the potential impacts of fluctuations in renewable generation will need to be accounted for explicitly during sizing. This has yet to be done; infact one of the conclusions of the review paper by Mahesh and Sandhu [42] was that more attention needs to be paid to the intermittency issue during design and sizing if the energy share of renewables is to increase.

The purpose of this paper is to present a methodology which allows both the intermittency and inter-year variability of renewable resources to be accounted for at the design stage in the sizing of hybrid energy systems integrating multiple renewable generation and energy storage technologies. The work will build on the methodology developed in our previous work [4] where we presented a methodology for accounting for renewables variability in hybrid system sizing. The framework developed here accounts for intermittent na- 
ture of power output from renewables by incorporating into the energy system model operational constraints which control the discharge of the available storage technologies. The impact of intermittency in renewables power output on the configuration and operation of energy systems will be assessed by comparing the results obtained in two case studies: one in which the intermittency is accounted for, and one in which it is ignored. The methodology developed ensures that the decision maker is furnished with sufficient information about a number of feasible designs and configurations based on which sizing decisions can be made.

\section{Accounting for the intermittent nature of renewable power output in energy systems design}

Renewables generation is susceptible to sudden,unscheduled fluctuations in output due to the intermittent nature of renewable resources. For standalone energy systems, such fluctuations must be accounted for at the design stage. While sudden spikes in generation level can be controlled by dumping some of the energy, sudden reductions in output will require some form of response from the storage systems. Thus, in order to provide smooth and uninterrupted power to any process from a renewable-based energy system, the storage options must be capable of responding quickly to such fluctuations, typically within milliseconds [40, 22 . For standalone solar-thermal generation technologies integrated with storage, this is not a problem because both the generation and storage units share the same thermal-to-electrical power conversion system [57, 41]. Such fluctuations must however be accounted for with electrical generation technologies, particularly wind generation. While the incorporation of forecasting techniques can help to alleviate some of the problem, weather forecasts still have some uncertainty associated with their predictions. Thus, the ability to respond quickly to such sudden weather fluctuations must be built into standalone energy systems at the design stage. Failure to do so could lead to significant losses in revenue and and possibly even equipment damage. There are a number of methods which may be employed to address this challenge. One alternative that may be considered is storage buffering. With this approach, no energy is sent directly to the plant from generation: all the demands of the plant are satisfied from storage. This ensures that while the input into the storage system may fluctuate, it does not affect power supply to the plant. The storage system therefore acts as a power regulator for the plant, providing a buffer between the variability and intermittency inherent in renewables generation and the stability required in power supply.

The buffering approach has two main drawbacks: first, it requires the oversizing of generation units to compensate for the increased losses from the system through storage. This is a serious challenge because the capital costs of generation technologies are typically the largest contributors to the hybrid system capital cost [32]. The storage system may also need to be oversized. The second drawback is that the approach 


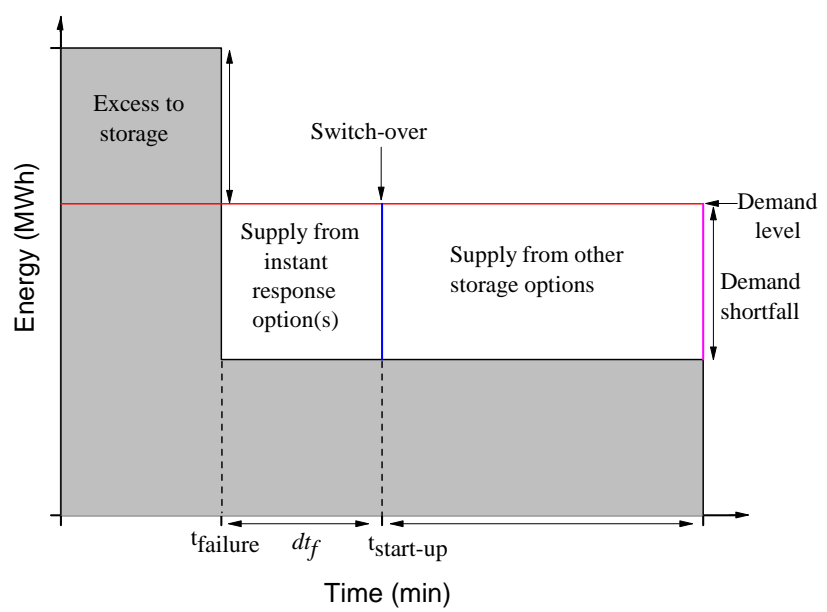

Figure 1: Schematic representation of energy system reaction to sudden drop in generation level. The shaded region shows the output from the generating units while the red line shows the plant demand level. Initially, generation is greater than plant demand and the storage options are in charging mode. When the sudden drop in generation occurs at $t_{\text {failure }}$, the storage options with instantaneous response come online. Other options come online after their response times $d t_{f}$ have elapsed.

leads to an increase in the operating and maintenance costs of the system since the storage systems will need to be in operation at all times. These cost-related drawbacks make the approach unattractive.

An alternative approach, considered in this work, is to incorporate the response times of the individual storage technologies and its potential impacts on the operation of the hybrid energy system into the sizing process at the design stage. With this approach, the earliest time a storage option may become available for use in the case of a sudden drop in renewable generation level (called the response or start-up time) is accounted for during design. The operating behaviour of the system when this approach is implemented is shown in Figure 1 Each storage option only comes online after its response time $d t_{f}$ has elapsed. For example, storage options such as batteries or supercapacitors which have instantaneous response times become available for use immediately after the fluctuation occurs.

To demonstrate the approach, we consider an energy superstructure for a remote mining operation with multiple generation and storage technologies available for selection as shown in Figure 2

Three renewable energy generation alternatives are considered: electricity generation via photovoltaics (PV) and wind turbines (WT), and thermal energy generation from power towers (PT).

Photovoltaics convert solar energy into electricity. The photovoltaic system consists of two components: solar panels, which convert solar energy into electricity, and power-point tracking inverter(s) which convert from direct to alternating current.

Wind turbines convert the kinetic energy available in wind into electrical energy.

Power towers convert solar energy into heat. The system consists of two main components: the heliostats 


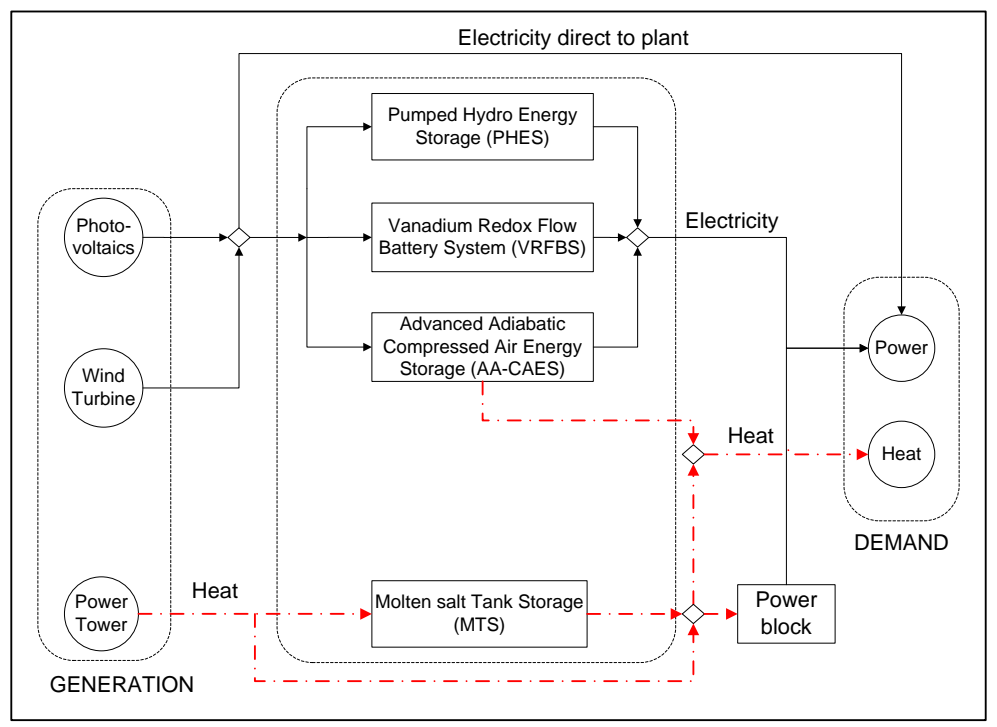

Figure 2: Proposed integrated energy system for mining operation. The solid black lines lines show the possible electricity network while the broken red lines represent heat.

(collectors) and the absorber. The sun-tracking heliostats reflect the direct portion of solar radiation which hits its surface onto the absorber where the concentrated thermal energy is transferred to the operating fluid (molten salt). For electricity generation, the hot salt is used to heat up steam for the power block which is comprised of a conventional steam turbine and generator system.

The excess energy generated is stored for use in times of insufficient generation. Molten salt tank storage (MTS) is employed for the storage of any excess thermal generation from the power tower. Three alternatives are available for the storage of excess electricity: pumped hydraulic energy storage (PHES), advanced adiabatic compressed air energy storage (AA-CAES) and vanadium redox flow battery storage (VRFBS). The storage alternatives were selected from the large number of alternatives available based on practical considerations such as technology maturity, large-scale power deliverability and technology depreciation time. The storage alternatives are fundamentally different in use and losses. Together, the four storage options should be able to cater for the requirements of any large scale continuous process. The methodology can be easily be extended to include new storage technologies which may become available subsequently.

The hybrid energy system is expected to meet the thermal and electrical demands of the plant. The electrical demands may be satisfied directly from $\mathrm{PV} /$ wind generation or from any of the storage options. The thermal load may be met either directly from the power tower or from the the AA-CAES or MTS systems.

For the superstructure described here, the aim is to identify energy system designs which trade-off between cost and performance while accounting for both renewables variability between years and the intermittent nature of renewables power output. We wish to generate designs capable of providing full demand satisfaction 
Table 1: Comparison of response times of storage options. For the PHES system, the response time is dependent on whether the required generator is already connected to the power system (spinning) or completely switched off (standing). The time reported for the solar thermal system assumes that the power block was used in the last 12 hours.

\begin{tabular}{ccc}
\hline Option & Response time & Source \\
\hline PHES & $10 \mathrm{~s}$ (spinning) & Kloess [38], Zach et al. [71] \\
AA-CAES & $>1 \mathrm{~min}$ (standing) & Kloess [38] \\
VRFBS & $15 \mathrm{~min}$ (cold start) & Luo et al. [40] \\
Power block for solar thermal technologies & $15-25 \mathrm{~min}$ (hot start) & Flueckiger et al. [24] \\
\hline
\end{tabular}

from local generation.

To see how the system would be affected by sudden changes in generation, we consider the start-up times of various storage technologies available in the superstructure. This is shown in Table 1. From the start-up times, it is clear that the battery system is the only electrical storage technology able to respond instantly to sudden reductions in power generation. Also, it is clear that transitioning from electrical generation to thermal generation (or thermal storage) for electricity supply cannot occur directly because of the startup time of the power block. In order to obtain energy system designs which are able to provide smooth, uninterrupted power, these technological limitations must be accounted for in the energy system model.

\section{Energy system model}

The full energy system model is described by models for the different generation and storage technologies available in the superstructure. Generation models are algebraic in nature, while storage technologies are typically represented by dynamic models. An energy system design will be defined by the capacities of the generation and storage units available within the superstructure.

Only equations for the energy system output and the objective functions will be presented here. A detailed description of the energy system model may be found in AppendixA. It contains descriptions and models for the wind generation and the battery storage systems, as well as summaries of the other technologies available within the superstructure. Detailed models for the other technologies have been presented elsewhere 3 .

\subsection{Renewable energy system output}

\subsubsection{Electrical output}

From Figure 2, the gross electrical output of the renewable energy system comprises of the power supplied directly from generation and the power output from the four storage options:

$$
\dot{E}^{R E S}(t)=\dot{E}^{d}(t)+\sum_{j=1}^{4} \dot{E}_{j}^{\text {out }}(t)
$$


However, the behaviour of the storage systems for electricity supply is dependent on the elapsed time since the last time energy was dispatched from storage (which corresponds to the most recent time direct generation $\dot{E}^{d}(t)$ was insufficient to meet demand). To account for the response time of the technologies, we introduce constraints which control the dispatch and operation of the storage systems during power generation fluctuations. The behaviour of the system is subdivided into states based on Fig. 1] The VRFB system responds in the immediate aftermath of any shortfall in generation, with the other options coming online sometime later. Assuming that the slow-reacting storage systems require the same length of time $t_{\text {start-up }}$ to become available, the states may be represented mathematically as:

$$
\begin{array}{ll}
\dot{E}^{R E S}(t)=\dot{E}^{d}(t) \quad \forall \mathrm{d} t_{f}=0 & \\
\dot{E}^{R E S}(t)=\dot{E}^{d}(t)+\dot{E}_{B A T}^{\text {out }}(t) & \forall 0<\mathrm{d} t_{f}<t_{\text {start }-u p} \\
\dot{E}^{R E S}(t)=\dot{E}^{d}(t)+\sum_{j=1}^{4} \dot{E}_{j}^{\text {out }}(t) \quad \forall \mathrm{d} t_{f} \geq t_{\text {start-up }}
\end{array}
$$

where $\mathrm{d} t_{f}$ represents the elapsed time since the start of the shortfall.

Eq. 2 represents the state of the system in which electrical generation exceeds electrical load. In this state, direct supply to the plant from generation is sufficient to meet demand; no energy is required from storage. The latter two states represent the behaviour of the energy system in the aftermath of shortfall in electrical generation. In the immediate aftermath of the shortfall $\left(\mathrm{d} t_{f}<t_{\text {start-up }}\right)$, only the VRFB system is available. The total output of the energy system is a combination of the outputs from battery storage and direct generation (Eq. 3). In this time period, the necessary steps are taken to power up the other storage technologies. Once sufficient time has elapsed $\left(\mathrm{d} t_{f} \geq t_{\text {start-up }}\right)$ the other storage options become available and the system moves to the third state (represented by Eq. 4).

With Eqs. 24, we are able to account for the different states of the system based on the time since the previous shortfall $\mathrm{d} t_{f}$ and the storage start-up time $t_{\text {start-up. }}$. Since $t_{\text {start-up }}$ is assumed to be the same for all the technologies, it must be selected to match the start-up time of the slowest technology. Thus, $t_{\text {start-up }}=15 \mathrm{~min}$. A smaller value of $t_{\text {start-up }}$ could lead to potentially infeasible designs; a larger $t_{\text {start-up }}$ to battery oversizing and increased system cost.

The assumption of a uniform start-up time reduces the number of states that need to be considered, simplifying the problem. This approach is particularly useful when a large number of storage technologies with varying start-up times are considered: the storage options would be grouped based on response time similarity. However, the problem can be modelled with individual start-up times for the different technologies if 


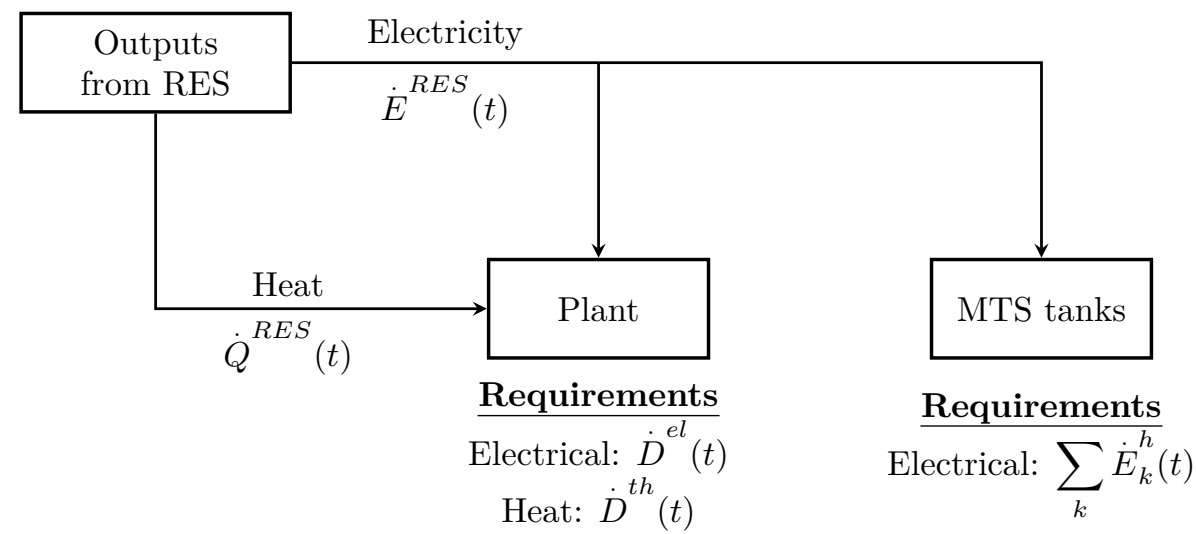

Figure 3: Schematic representation of the energy requirements of the plant. Part of the electricity generated is used to provide the heating to the two MTS storage tanks $k$. This extra load reduces the total energy available for plant demand satisfaction.

necessary. In that case, this system will have four states rather than the three considered here.

\subsubsection{Thermal output}

The total heat supplied from the energy system to satisfy the thermal demand is

$$
\dot{Q}^{R E S}(t)=\dot{Q}_{A A-C A E S}^{\text {heating }}(t)+\dot{Q}_{M T S}^{\text {heating }}(t)
$$

Here, $\dot{Q}_{M T S}^{\text {heating }}(t)$ represents the total heat supplied from both the power tower and MTS systems (see Figure 2), while $\dot{Q}_{A A-C A E S}^{\text {heating }}(t)$ represents the heat supplied from the AA-CAES system.

\subsubsection{Load demands}

Figure 3 presents a schematic representation of the loads that must be met by the energy system. The energy system must satisfy not only the requirements of the mine $\left[\dot{D}^{e l}(t), \dot{D}^{t h}(t)\right]$, but also the electricity requirements of the heaters of the molten salt storage tanks. Thus, the total electrical load to be satisfied $\dot{E}^{\text {load }}(t)$ is actually greater than the electrical demand of the mine $\dot{D}^{e l}(t)$. Under ideal conditions, the heat and power outputs of the renewable energy system satisfy the total demands of the plant $\left[\dot{E}^{\text {load }}(t), \dot{D}^{\text {th }}(t)\right]$. The system is considered to have failed when the supply from the energy system does not meet either (or both) of these demands. In such a case, ancillary support (such as diesel generation) would be required to meet the shortfall to ensure that the operation suffers no downtime.

Equations 255, coupled with those presented in AppendixA for the wind generation and battery storage systems and those previously presented for the other system components in Amusat et al. [3], form the 
energy system model. Based on the model, eleven variables are required to define an energy system design,

$$
\bar{x}=\left\{C_{P V}^{g e n}, C_{P T}^{g e n}, N_{W T}, C_{j}^{s}, C_{j}^{\text {out }}, N_{b a t}, N_{s t}\right\} ; \quad j \neq \mathrm{VRFB}
$$

where $j$ here represents the set of available storage alternatives other than the VRFB system (PHES, AACAES, MTS). For the battery system, the number of battery units $N_{b a t}$ and the number of storage hours $N_{s t}$ are considered as the design variables in place of the capacity variables $\left\{C_{B A T}^{s}, C_{B A T}^{o u t}\right\}$. This was done because the VRFB storage capacity $C_{B A T}^{s}$ can only take on certain discrete values depending on $N_{b a t}$ which must be an integer (see Eq. A.8). Thus, considering $N_{b a t}$ as a design variable is a better approach for the battery system. For the same reason, the number of wind turbines $N_{W T}$ (which must be an integer) is considered in place of the wind turbine nominal capacity $C_{\text {wind }}^{\text {gen }}$. The two variables are related by Eq. A.2 The model allows us to evaluate the performance of any design given the appropriate renewable input data.

\subsection{Objective functions}

Both economic and quality performance considerations need to be weighed in the evaluation of any energy system design.

\subsubsection{Economic criteria: cost function}

The cost objective considered in this work is the capital cost of the integrated energy system. It consists of the investment costs of the generation and storage technologies. Generation technologies are generally costed based on the nominal power output $\left(C_{i}^{g e n}\right)$ or installed areas $\left(A_{i}^{g e n}\right)$. The capital cost of storage technologies is dependent on both the total energy capacity $\left(C_{j}^{s}\right)$ and the peak discharge power $\left(C_{j}^{\text {out }}\right)[38$, 28]. The capital cost of any design may be evaluated as:

$$
C C=\sum_{i=1}^{n_{g}} U_{i}^{g e n} A_{i}^{g e n}+\sum_{j=1}^{n_{s}}\left(U_{j}^{s} C_{j}^{s}+U_{j}^{\text {out }} C_{j}^{\text {out }}\right)
$$

where $n_{g}$ and $n_{s}$ are the number of generation and storage options, and $U_{i}^{g e n}, U_{j}^{s}$ and $U_{j}^{\text {out }}$ are the unit costs of the generation (per $\mathrm{m}^{2}$ ), storage (per Wh) and discharge units (per W) respectively.

\subsubsection{Performance criteria: energy system reliability}

In order to be able to compare any two designs we need to take into consideration not just their costs but also how well both designs perform in demand satisfaction, or how reliable the designs are. The modified loss 
of power supply probability [3, 4, which measures how frequently a design is unable to produce an expected (or desired) level of performance, is considered as the reliability criteria:

$$
\overline{\operatorname{LPSP}}_{m}=\frac{\text { Number of years with unsatisfactory performance }}{\text { Total number of years considered, } N_{\text {year }}}
$$

It is an indication of the frequency of failure of the given design. For example, a design which is able to produce the expected performance in six out of ten years will have a $40 \%$ failure rate, or $\overline{L P S P}_{m}=0.4$. Thus, the measure allows us to actually quantify the effect of climate-based variability.

The target in this work is to generate designs which provide full demand satisfaction from local generation. A design fails when once the output of the RES is unable to meet the load demand (thermal or electrical) at any time within the year. Thus, if each complete year of renewables input data (solar and wind) is considered be an independent input scenario and $E E$ is the total external energy requirement in a given scenario, then the reliability criteria for the problem may be written as

$$
\overline{\operatorname{LPSP}}_{m}=\frac{\text { Number of scenarios in which external energy is required to meet demand }}{\text { Total number of input scenarios considered, } N_{\text {year }}}=\frac{\left.N_{\text {year }}\right|_{\text {EE }>0}}{N_{\text {year }}}
$$

The objectives quantify all potential designs in economic and performance terms, allowing us to easily compare any two designs or configurations of the energy system.

\section{Full bi-criteria design problem}

Based on the system model described in the section 3 , the full sizing problem may be defined as follows:

\section{Given:}

- a number of renewable input scenarios representing the renewables availability and variability at the location,

- the unit costs of the generation and storage technologies $\left(U_{i}^{\text {gen }}, U_{j}^{s}, U_{j}^{\text {out }}\right)$,

- the efficiencies of all mechanical components (turbines, pumps and compressors), and

- the electrical and thermal load demands of the plant,

generate a trade-off curve containing a set of energy system designs $\bar{X}=\left\{\bar{x}_{1}, \bar{x}_{2} \ldots \bar{x}_{n}\right\}$ which minimize the capital cost of the system $C C(\bar{x})$ and the loss of power supply probability $\overline{L P S P}_{m}(\bar{x})$ subject to generation, 
storage, capacity and operational constraints. Mathematically,

$$
\min _{\bar{x} \in \bar{X}} z=\left\{\begin{array}{l}
F_{1}(\bar{x})=C C(\bar{x}) \\
F_{2}(\bar{x})=\overline{L P S P}_{m}(\bar{x})
\end{array}\right.
$$

The decision maker would then be required to select a design from the available alternatives $\bar{X}$.

Evaluating the energy system reliability requires input information about the performance of the energy system under a variety of renewable input conditions. We therefore need renewables data which reflects the variability at the location of the mine. Generating this data will be the focus of the next section.

\section{Renewables scenario generation}

Renewable input data which represent both the renewables availability and variability at the site under consideration are required to evaluate the reliability of designs accurately. Historical recordings are the best source of input data but are often insufficient or incomplete, and part or all of the renewables data must be obtained by other methods. For such cases, synthetic data (or scenarios) with properties similar to what would be observed at the site must be generated. One way to ensure that the synthetic data generated is realistic and has the right characteristics is to base the synthetic data on the statistical properties of the available historical data.

Two types of renewable resources have been considered in the energy system: wind and solar. Thus, each renewable input scenario needs to contain data for both renewable types at every instant in time throughout the year. Generation of synthetic renewable input scenarios therefore consists two steps:

- Model development for different renewable input types, and

- Generation of renewable input scenarios containing both wind and solar information.

Both steps will be discussed in further detail.

\subsection{Renewables modelling}

The first stage involves the development of statistical models for the different renewable input types required by the energy system model. Three different generation technologies available in the superstructure (Figure 2), with each requiring a different type of renewable input. Statistical models and methodologies which allow us to generate synthetic data for the different renewable input types are required. 
Basing the profiles on the properties of historical data means that the wind and solar input profiles will be generated independent of each other.

\subsubsection{Windspeed modelling}

The power output from wind turbines is dependent on the windspeed availability at the selected site. Most meteorological stations collect instantaneous windspeed data, typically hourly or half-hourly. In order to account for climate-based variability, we characterize the historical data for each time step of each month by a probability distribution function. The Weibull distribution, which has been shown in literature to be the most appropriate distribution for windspeed data [25, 62, 44, is used here. The probability density function (PDF) and cumulative distribution function (CDF) of a Weibull distribution are given by:

$$
f(\vartheta)=\frac{\beta}{\alpha}\left(\frac{\vartheta}{\alpha}\right)^{\beta-1} e^{-\left(\frac{\vartheta}{\alpha}\right)^{\beta}}
$$

and

$$
\mathcal{F}(\vartheta)=1-e^{-\left(\frac{\vartheta}{\alpha}\right)^{\beta}}
$$

where $\vartheta$ is the wind speed, and $\beta$ and $\alpha$ are the shape and scale parameters respectively. The shape parameter $\beta$ determines what the distribution will ultimately look like, while the scale parameter $\alpha$ determines the height and width (spread) of the distribution. Expressions for evaluating the scale and shape parameters of the Weibull distribution may be found in Gooding et al. [26, 27.

Random windspeed realizations from the Weibull distributions were generated using MATLAB's in-built Weibull random data generator wblrnd. A single realization of the windspeed for any time step $h$ of any day $d$ of any month $m$ can be obtained by random data generation from the appropriate $\operatorname{distribution} f\left(\vartheta_{m, h}\right)$. This approach has been used extensively in literature for simulating full years of synthetic windspeed data 6. 37, 9, 63.

Based on the statistical model, complete years of windspeed data (wind profiles) can easily be generated. The windspeed at any time is modelled as a linear combination of two terms,

$$
\begin{array}{ll}
v_{m, 1, h}=f\left(\vartheta_{m, h}\right) & m=1,2 \ldots 12 ; \quad h=1,2 \ldots, n_{s} \\
v_{m, d, h}=\omega_{d} \cdot v_{m, 1, h}+\left(1-\omega_{d}\right) \cdot f\left(\vartheta_{m, h}\right) & d=2 \ldots, n_{\text {days }}
\end{array}
$$

where $\omega_{d} \epsilon[0,1]$ is a weighting factor which provides a balance between individuality and trend in the data: the larger its value, the more the trend in the monthly data. 
The first term ensures that days within the same month have some degree of similarity, providing a trend-like contribution. A value of $w_{d}=1$ indicates that all the days of the month are expected to have exactly the same wind conditions. This increases the chances of covering rare events such as entire windy month. The second term provides individuality to the data, ensuring that the days of the month are different from each other in some way.

A value of $w_{d}=0.5$ was selected for the generation of the synthetic radiation profiles in this work, meaning that both the daily and monthly approaches contribute equally to the final profile for each day. Thus, the approach allows us to capture both the short term similarities in weather data (captured by the first term) and the long term variations in climate data (captured by the second term).

As in all other works involving synthetic data generation from probability distributions [6, 37, 9, 63, 4, the approach assumes that windspeed available in consecutive time periods are dependent solely on the relevant probability distribution: $v_{m, d, h}$ is not influenced by $v_{m, d, h-1}$. However, the methodology is general and allows for other types of trends and properties (such as relationships between consecutive hours) to be added to the wind profiles.

Equation 12 may be used to generate as many windspeed profiles $n_{\text {wind }}$ as are desired.

\subsubsection{Solar radiation modelling}

Two types of solar radiation data are required based on the technologies available in the superstructure. Photovoltaics require global horizontal irradiance (GHI) data, while power towers require direct normal irradiance (DNI) information. Details about GHI and DNI data generation have been presented in detail in previous works [3, 4, so only summaries will be presented here.

The historical GHI data for each time step of each month is characterized using the Pearson family of distributions [54]. We have shown in a previous work [4] that the Pearson family of distributions perform well for solar modelling, producing good predictions daily, monthly and annually. Random GHI realizations from the family of distributions were generated using MATLAB's in-built pearsrnd function which generates random data from the appropriate Pearson distribution. Complete years of GHI data were modelled using the same approach described for windspeed,

$$
\begin{array}{ll}
\dot{G}_{m, 1, h}^{\text {tot }}=f\left(g_{m, h}\right) & m=1,2 \ldots 12 ; \quad h=1,2 \ldots, n_{s} \\
\dot{G}_{m, d, h}^{t o t}=\omega_{d} \cdot \dot{G}_{m, 1, h}^{\text {tot }}+\left(1-\omega_{d}\right) \cdot f\left(g_{m, h}\right) & d=2 \ldots, n_{\text {days }}
\end{array}
$$

The approach was repeated to generate the $n_{\text {solar }}$ GHI profiles required. 
The DNI profile corresponding to each GHI input profile was generated using the Louche model [39, 3 .

With these models, we are able to generate multiple independent solar and wind input profiles. The capability of the approach to generate good synthetic input profiles has been demonstrated previously [3].

The results of the of the data generation stage consists of $n_{\text {solar }}$ solar and $n_{\text {wind }}$ wind input conditions generated independently of each other. However, a renewable input scenario must consist of both solar and wind input data. Thus, the two data types need to be combined in some way. While the ideal approach would be to consider all $n_{\text {solar }} \times n_{\text {wind }}$ combinations of the solar and wind profiles, such an approach would require significant computational expense. We therefore to select a subset of renewable input scenarios from the full $n_{\text {solar }} \times n_{\text {wind }}$ set, sufficient to explore the entire space while reducing the computational requirements. Stratified random sampling is used to achieve this.

\subsection{Renewables scenario selection using stratified random sampling}

Stratification is the process of dividing members of a population into subgroups before sampling. In stratified random sampling, the population is divided into a number of non-overlapping sub-regions (called strata) based on a stratification criteria, with each sub-region then randomly sampled independently [10]. All the subgroups of the population are therefore represented in the final sample population [46. Stratified random sampling reduces selection bias, producing a sample population representative of the entire population under consideration. It is therefore a better option than random sampling [46].

In this work, the total renewables availability is considered as the criteria for stratification. Consider a set of solar and wind input conditions of the same size $n=n_{\text {solar }}=n_{\text {wind }}$. Each input type is sorted based on the renewables availability level and then divided into $q$ strata, each containing $n / q$ profiles. Thus, $q^{2}$ subregions are created from which samples may be selected, with each subregion containing $(n / q)^{2}$ potential renewable input conditions. This is demonstrated in Figure 4 for $n=4$ and $q=2$. Scenarios can then be selected randomly from each sub-region. In our case, we select $n$ renewable input scenarios randomly from each sub-region such that each renewable input condition is represented exactly once. This means that each point is selected $q$ times in total. The total number of scenarios selected is therefore reduced from $n^{2}$ to $n \cdot q$. Figure 4 shows a case where the number of renewable scenarios to be considered is reduced from 16 to 8 .

The approach reduces to pure random sampling when $q=1$ and becomes the evaluation of the whole set when $q=n$. It becomes more accurate as the number of strata considered is increased $(q \rightarrow n)$. It allows for the exploration of different types of input scenarios while reducing the computational requirements significantly. 


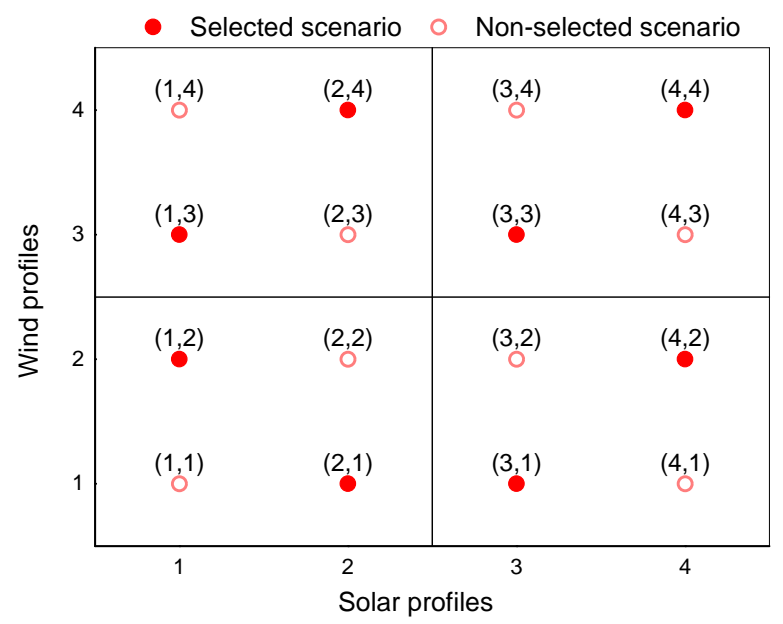

Figure 4: Demonstration of stratified random sampling approach for scenario selection. Each input type (with $n=4$ profiles each) is divided into $q=2$ strata, creating $q^{2}=4$ sections for sample selection. The selection of scenario $(1,2)$ eliminated the $(1,1)$ and $(2,2)$ scenarios from consideration.

To summarize, the generation of renewable input scenarios is done in two stages. First, data for each input type (solar and wind) are generated from appropriate probability distributions and correlations. This yields solar and wind input profiles generated independently of each other which represent the degree of variability at the location. A manageable number of scenarios are then selected from the set formed by the solar and wind profiles using stratified random sampling.

The selected scenarios form the time-series data input into the energy system model. The energy system model outputs information about how well a given design performs in each of the input scenarios. This information is necessary for reliability evaluation (Eq. 8). The next section describes how the energy system model is implemented for the evaluation of design performance in each scenario.

\section{Model implementation for reliability evaluation}

The model representing the energy system as described in Section 3 is a differential-algebraic system, with the generation systems represented by algebraic equations (for example, Eq. A.1) and the storage systems by dynamic equations (such as Eq. A.7. The model equations are discretized using the forward Euler method. An Euler discretization is sufficient for the problem as the system is non-stiff. The discretization divides

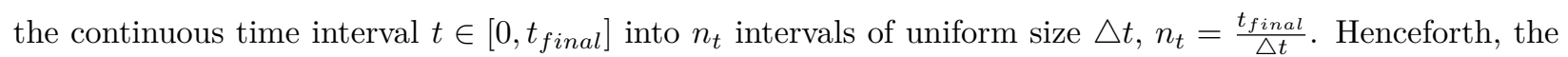
subscript $\tau$ is used to represent the time-dependent variables in the discrete problem, $\tau=0,1, \ldots, n_{t}$.

The discretized model has been implemented in MATLAB in a step-wise manner. For each input year of data, the energy system model is evaluated by repeating the following steps for each $\tau$ : 


\section{Evaluation of instantaneous generation}

The instantaneous output of each generation option is evaluated based on the current renewables availability.

\section{Demand satisfaction}

Next, the routes by which the demands of the mine are satisfied are determined. Two factors were considered in determining the way in which the energy system should be operated:

- the form of energy generation and storage (thermal or electrical), and

- the types of losses associated with the storage systems.

Since there are fewer number of generation and storage options available for thermal energy supply, the thermal demands of the mine are satisfied first.

\section{(a) Thermal demand satisfaction}

Thermal energy supply from the power tower and MTS systems are considered first for thermal load satisfaction. If those options are unable to satisfy the thermal load, energy from the thermal energy store (TES) of the AA-CAES is then considered. Any unmet thermal load $\dot{S}_{\tau}^{\text {th }}$ must then be supplied from outside the renewable energy system.

\section{(b) Electrical demand satisfaction}

Next, the satisfaction of the electrical load of the plant is considered. Figure 5 presents a schematic representation of the system operation for electrical load satisfaction.

First, the model determines whether the electrical load demand $\dot{E}_{\tau}^{\text {load }}$ can be satisfied fully from electrical generation $\dot{E}_{\text {total, } \tau}^{g e n}$. When this is possible, direct supply from generation $\dot{E}_{\tau}^{d}$ powers the plant. There is no energy shortfall and no need for external energy supply. Any excess electrical generation is sent to storage. Thus, the storage systems are in charging mode.

When the electrical generation is less than the electrical load demand $\left(\dot{E}_{\text {total }, \tau}^{\text {gen }}<\dot{E}_{\tau}^{\text {load }}\right)$, the plant is in discharge mode as the electrical shortfall $\dot{S}_{\tau}^{e l}$ must be supplied either from storage or from outside the renewable energy system. The decision on which storage options are available at any time is determined by a binary variable $\psi_{\tau}$ which tracks the storage system state:

$$
\psi_{\tau}= \begin{cases}1 & \text { when } \sum_{j=1}^{4} \dot{E}_{j, \tau}^{\text {out }}>0 \\ 0 & \text { otherwise }\end{cases}
$$

Considering the value of $\psi$ at the previous time step provides information on the previous state of the system. A value of $\psi_{\tau-1}=0$ means that none of the storage options was in use at the 


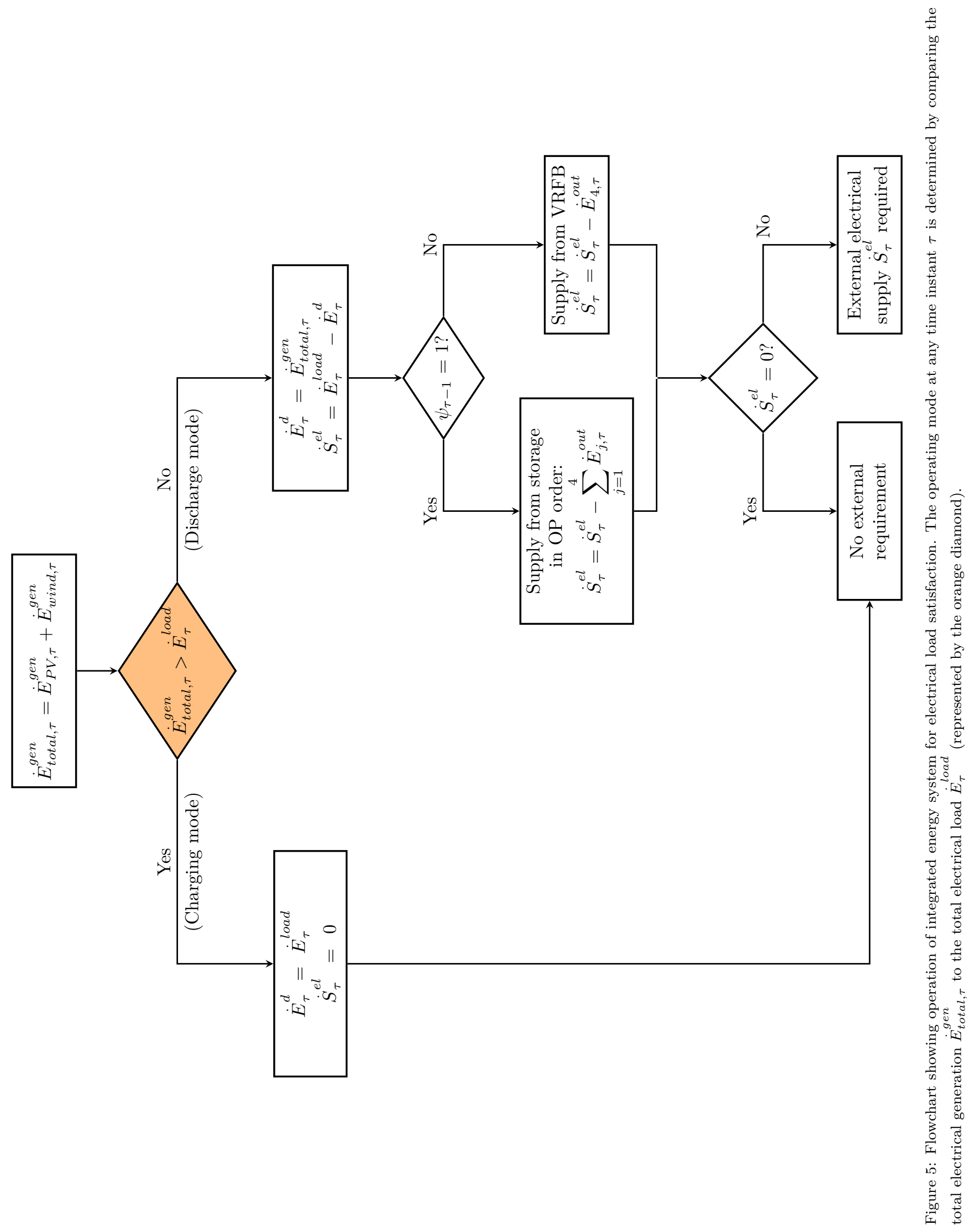


previous time period. This indicates that the entire electrical load in the previous time step $\dot{E}_{\tau}^{\text {load }}$ was supplied directly from electrical generation. Thus, a transitioning period is required to allow for start-up of the storage systems. During this period, only the battery bank (taking advantage of its instantaneous response) is available for use.

A value of $\psi_{\tau-1}=1$ indicates that at least one storage option was active at the previous time step, indicating that sufficient time has elapsed for all the storage systems to become available. In this case, the discharge order is dependent on a pre-defined operating scheme for storage $\overline{O P}$. There is therefore an implicit assumption here that the power output of the storage units can be increased or decreased rapidly as long as the system is already operational.

The approach implemented here assumes that one time step represents sufficient time for the other storage options to become available. However, the condition can easily be modified for technologies requiring longer start-up times without changing the time resolution $\triangle t$. For a technology with a start-up time $t_{\text {start-up }}$, the number of elapsed time steps that is required is given by $n_{\text {step }}=t_{\text {start-up }} / \Delta t$. Thus, the technology does not become available until $n_{\text {step }}$ consecutive time steps have elapsed,

$$
\left\{\psi_{\tau-1}, \psi_{\tau-2}, \ldots \psi_{\tau-n_{s t e p}}\right\}=1
$$

It should be noted that this has no impact on the search space as it is not a combinatorial problem. The approach therefore allows for finer time resolution without implying faster startup times. The variable $\overline{O P}$ determines the order in which the storage options are discharged. Four storage options are available for selection; this equates to $4 !=24$ possible operating orders. However, we do not need to explore all the alternatives because the order of discharge of some of the storage technologies can be fixed based on factors such as losses, use and costs:

- The battery system should be discharged last when $\psi_{\tau-1}=1$. The battery system is the storage option available in the superstructure with instantaneous response, and is the most expensive of the storage options. It is therefore reasonable to try to avoid using the system when other (cheaper) storage options are available.

- The AA-CAES system should be discharged before the PHES system. This order is based on the nature of the losses from the two systems. The PHES system only incurs mechanical losses when the system is in operation. On the other hand, the AA-CAES system incurs losses (mechanical and thermal) whether the system is in operation or not. Thus, we have chosen to discharge the AA-CAES first when energy is available in both storage options in order 
Table 2: Electrical charging and discharging orders for storage technologies

\begin{tabular}{lc}
\hline System state & Available orders \\
\hline \multirow{2}{*}{ Discharging } & $\overline{O P}=1:$ AA-CAES $>$ PT-MTS $>$ PHES $>$ VRFB \\
& $\overline{O P}=2:$ AA-CAES $>$ PHES $>$ PT-MTS $>$ VRFB \\
Charging & VRFB $>$ PHES $>$ AA-CAES \\
\hline
\end{tabular}

to reduce the standing losses to the minimum. The two storage types can still be selected individually or together, as will be seen in the results. Further details about this decision and its potential impacts may be found in Amusat et al. [4.

These constraints reduce the potential storage discharge orders from 24 to three (shown in Table 21. $\overline{O P}$ is a design variable which selects between the three schemes. It should be noted that the solar thermal generation and storage systems (PT and MTS) are treated as one unit in the decision-making process because they share a power block. Once the decision is made to switch on the power block for electricity generation (based on $\overline{O P}$ ), both PT and MTS are used: first the PT for direct supply, then the MTS.

Two designs with the same unit capacities but different operating schemes will have the same capital cost but potentially different reliabilities. Thus, a fully defined design will provide information about both the sizes of the units and how the storage systems will be operated,

$$
\bar{x}=\left\{C_{P V}^{g e n}, C_{P T}^{g e n}, N_{W T}, C_{j}^{s}, C_{j}^{o u t}, N_{b a t}, N_{s t} \mid \overline{O P}\right\} ; \quad j \neq \mathrm{VRFB}
$$

The electrical power output of any storage system is dependent the unmet electrical load $\dot{S}_{\tau}^{e l}$, the current storage state $E_{j, \tau}^{s}$, and the peak output capacity of the storage system $C_{j}^{\text {out }}$. The unmet load is updated after the dispatch each storage option. The new level of energy in the storage unit is also updated. This procedure continues until all the storage options have been dispatched. Once the outputs of the storage options have been determined, the unmet electrical load $\dot{S}_{\tau}^{e l}$ can easily be estimated. A value greater than zero indicates that some of the electrical demands will need to be satisfied from outside the renewable energy system.

The total external energy requirement of the mine is the sum of the unmet thermal and electrical loads over the entire time interval, $E_{\tau}^{e x t}=\left[\dot{S}_{\tau}^{e l}+\dot{S}_{\tau}^{t h}\right] \cdot \Delta t$.

\section{Storage charging and evaluation of dumped energies}

Next, the end states of the storage options (which will serve as the starting storage levels in the next time step $\tau+1)$ are evaluated. The order for charging the electrical options is shown in Table 2 The battery system is charged first since it is the only instantaneous response option. The PHES system 


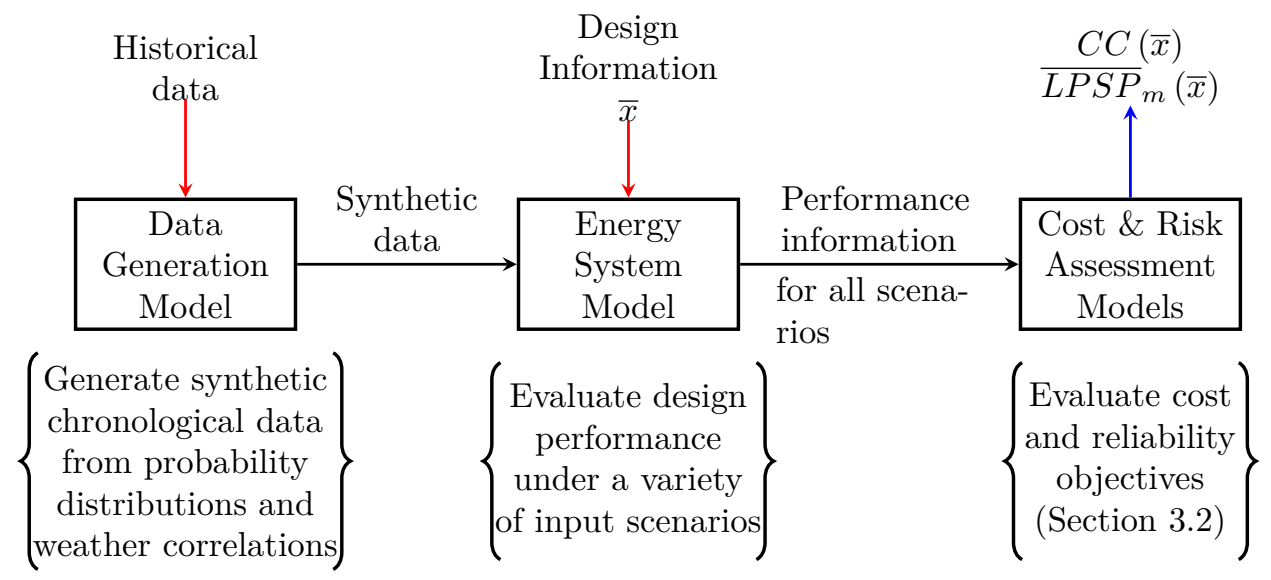

Figure 6: Summary of design evaluation process.

is charged before the AA-CAES system because it has no standing losses - energy stored in the PHES system does not reduce in quantity or quality when the system is not in operation. Any electricity left over after the three options have been fully charged is dumped.

The MTS is charged with thermal energy from the power tower. The left-over thermal energy after the storage tank is fully charged is returned as the dumped thermal energy.

These steps are repeated for all $n_{t}$ intervals. At the end of the procedure, the total energy required from outside the hybrid energy system for the year may be evaluated as

$$
\text { Total external requirement, EE }[\mathrm{MWh}]=\sum_{\tau=0}^{n_{t}} E_{\tau}^{e x t}
$$

The frequency and duration of energy system failure can also be calculated easily.

The performance data obtained from the model implemented here form the input information required for the evaluation of the energy system reliability (Eq. 8).

In summary, to evaluate any given design, a set of renewable input scenarios is first generated from appropriate probability distributions and weather correlations (Section 5). The performance of the design under each of the generated renewable availability scenarios is evaluated with an energy system model which incorporates constraints on the dispatch and operation of the storage systems during power generation fluctuations (Sections 6). The information from the energy system model is then used to evaluate the design reliability and cost as detailed in Section 3.2 The intermittent nature of the power outputs from renewables generation technologies is accounted for in the energy system model while the climate-based variability is accounted for by considering multiple renewable input conditions. Figure 6 is a schematic representation of the process. 
Two assumptions made in the development of the methodology need to be highlighted:

1. The renewable input data and load data supplied to the model are lumped; it is assumed that the availability and load values are constant over a given time interval. This is done because minute-byminute renewables data is unavailable. As a result, the power outputs of the generation and storage units will appear to change in a step-wise, discontinuous manner between time intervals (for example, from a constant $40 \%$ of output capacity in one time period to $0 \%$ in the next). We do not mean to imply that this is actually the case: in reality, power outputs will change gradually from one minute to the next until the cut-off point is reached, at which point the output from the system falls to zero. However, this cannot be represented appropriately here and is a limitation of the data available, not the model itself. Given finer input data granularity (minute-by minute data) and additional computational resources, the model is capable of producing a more realistic behaviour.

2. While the model accounts for start-up times of the different storage technologies, we have assumed instantaneous ramp rates once they are operational. In reality, different storage technologies have different load following capabilities and this will have an impact on the choice and/or operation of the technologies. Technologies with low ramp rates will require battery support for longer. While the issue of ramp rates will not be addressed in this work, the storage technologies available on the superstructure are known to have have good ramping capabilities. Flow batteries are considered to be one of the best technologies for ramping/load following due to their instantaneous response capabilities [40], while Chen et al. 14] suggests that PHES and CAES systems are suitable for load following. Similarly, CSP plants with thermal energy storage are capable of being ramped very quickly (relative to conventional generators), with the ability to go from minimum to maximum operating capacity in under 10 minutes [17, 18. Any energy system configuration generated will therefore have good ramping capabilities. The methodology presented here can be adapted to account for ramp rates using the battery system, and this will be addressed in future works.

Both assumptions represent deviations from reality and will influence the results obtained from the model. Despite these limitations however, incorporating the storage start-up times allow us to better represent the availability and real-time operating behaviours of the individual storage systems. This is a significant step forward as we are then able to account for both the intermittent and variable nature of renewable resources in the design of hybrid energy systems.

Having established how the two objectives will be evaluated for any given design, the full design problem (Equation 9) can now addressed. 


\section{Solution methodology}

The bi-objective problem to generate the non-dominated set of designs is solved using NSGA-II [16, a nondominated sorting-based multiobjective evolutionary algorithm (MOEA). The MATLAB implementation of the algorithm by Song [59] is used. Figure 7 shows the flowchart for the process. As can be seen in the figure, a single set of renewable input profiles to be used for performance evaluation is generated before the stochastic solution procedure begins. This ensures that all the designs are compared on the same basis.

Genetic algorithms are the most widely used method for solving problems involving hybrid energy system sizing because of their ability of to jump out of local minimas, even for large problems with infinite number of design variables [21]. This means that the tractability and convexity problems which affect gradient and branching-based solvers are avoided. As with all evolutionary algorithms however, the use of a genetic algorithm introduces a stochastic element to the solution procedure. Multiple instances of the problem will need to be solved to obtain a measure of confidence in the results of the procedure.

\section{Case studies}

Two case studies are considered to evaluate the proposed methodology. In the first (base) case, the statedependent nature of storage availability (see Section 3.1) is ignored in the sizing of the energy system. All the storage technologies are assumed to be able to respond instantly to sudden fluctuations in generation irrespective of previous state. The case will explore the characteristics of the design solutions obtained when all the storage technologies are made available for use at all times. The base case design problem will therefore account solely for inter-year variability. The second case study incorporates both inter-year variability and renewables generation intermittency: the time-constrained storage response to sudden changes in renewable resource level is accounted for. Comparing the results obtained in both cases will provide an insight into how accounting for fluctuations in renewable generation during the design process can influence the sizing and configuration of hybrid systems. Some insight can also be gained into the operation of the plant, although this will be subject to the constraints imposed on the design space by the pre-defined operating scheme.

For the studies, we consider the sizing of an energy system for a fictional mine located in Alberta, Canada (Lat. $51.0^{\circ} \mathrm{N}$, Long. $114.0^{\circ} \mathrm{W}$ ). Alberta experiences large variability in renewables availability and is the hub of significant mining activities, especially oil sand and coal mining. Eight years of historical solar radiation data (2005-2012) for the location were obtained from the National Renewable Energy Laboratory [49. The database provides half-hourly solar irradiance measurements for any North American site, with data available from 1998. Wind velocity data covering the same period was obtained from the Department 


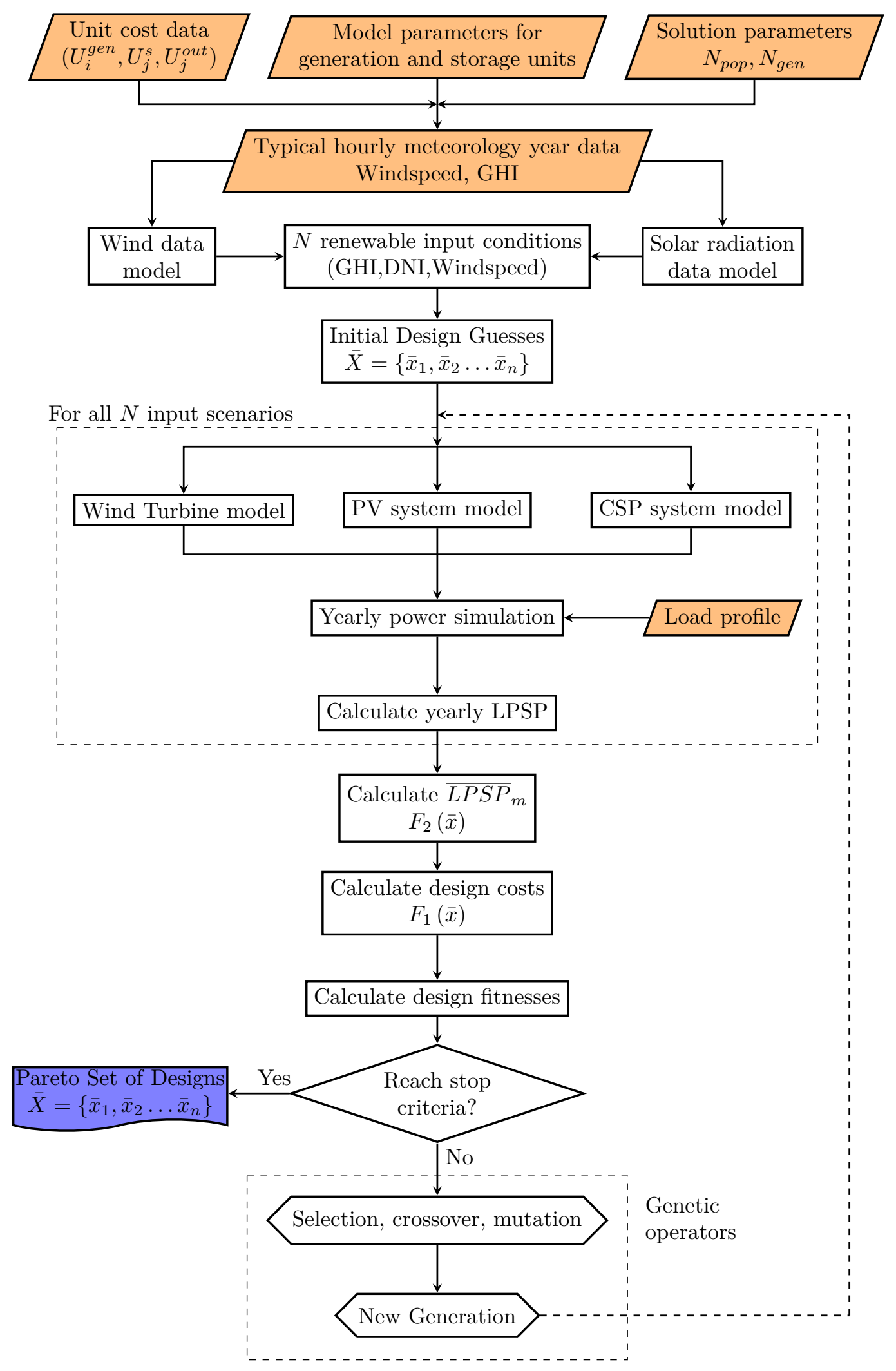

Figure 7: Flowchart for optimal sizing using multi-objective genetic algorithm. The input requirements for the scheme are highlighted in orange. 


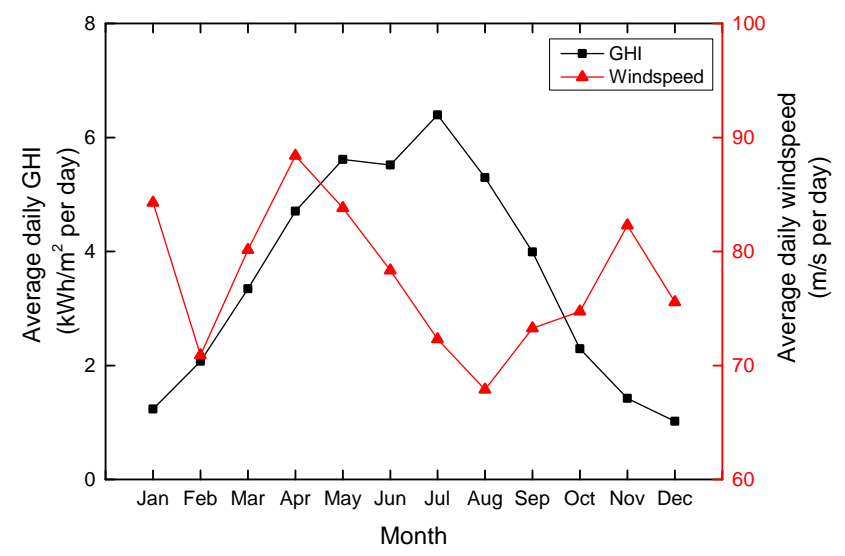

Figure 8: Average daily GHI and windspeed profiles for Alberta, Canada.

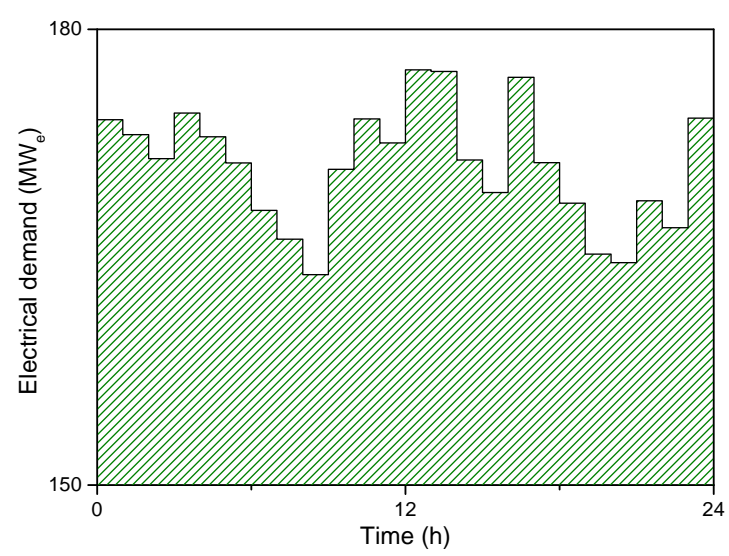

Figure 9: Daily electricity demand profile for the mine. The profile was assumed to be constant for all days of the year.

of Environmental and Natural Resources, Government of Canada [19]. Figure 8 shows the mean solar and windspeed availability at the location through the year.

Based on the statistical properties of the historical data, 300 potential profiles for each input type (solar and wind) were generated using the approach described in Section 5.1. The profiles were paired using stratified random sampling with $q=4$, giving a total of 1200 input scenarios.

Figure 9 shows the electrical load profile considered in this work. The profile was obtained from the actual electricity consumption data of a Chilean mine in July 2013. The demand does not vary significantly during the day: the maximum deviation from the mean demand of $171 \mathrm{MWh}$ is $4.2 \%$. The thermal demands of the plant were assumed to be $10 \%$ of the electrical demands due to lack of data. With direct heating accounting for $13 \%$ of the mining industry's energy end-use [55], the assumption was considered reasonable.

The parameters and cost data for the wind turbine and battery systems are presented in Table 3 Details about the parameters and cost data used for the other technologies and their sources may be found in Amusat et al. 3]. Table 4 shows the NSGA-II parameters used in the study.

\subsection{Base case}

For the base case, the response times of the storage technologies are not accounted for: all storage options are immediately available in the aftermath of sudden generation failure. This means that the constraints which control the dispatch and operation of the storage systems (Eqs. 2.44 do not apply: all the storage options are available for use at all times (Figure 5),

$$
\psi_{\tau}=1 \quad \forall \tau
$$


Table 3: Parameters used in case studies

\begin{tabular}{|c|c|c|c|}
\hline Generation/Storage & Description & Cost(s) & Source $(\mathrm{s})$ \\
\hline Wind turbine & $\begin{array}{l}\text { NEG Micon NM44 } / 750: P_{R}=750 \mathrm{~kW} \\
H=56 \mathrm{~m}, \nu_{c, \text { in }}=3.5 \mathrm{~m} / \mathrm{s}, \nu_{r}=15 \mathrm{~m} / \mathrm{s}, \\
\nu_{c, \text { out }}=25 \mathrm{~m} / \mathrm{s}, \text { power density }=2.03 \mathrm{~m}^{2} / \mathrm{kW}\end{array}$ & $907.1 € / \mathrm{m}^{2}$ & $\begin{array}{l}\text { Kavasseri and } \\
\text { Seetharaman } \\
\text { 35, National Renewable } \\
\text { Energy Laboratory, NREL } \\
\text { [50, The Wind Power [61] }\end{array}$ \\
\hline VRFB system & $\begin{array}{l}\text { Based on RedT } 5 \mathrm{KW}_{\mathrm{e}} \text { VRFB systems: } \\
\kappa=0 \% \text { per month. } U_{b a t, \text { single }}=40 \text { Volts. } \\
\text { DC-DC stack efficiency }=0.8 . \\
D O D_{\max }=0.8 \\
\eta_{i n v, a c-d c}=\eta_{i n v, d c-a c}=0.95\end{array}$ & $\begin{array}{l}200 € / \mathrm{KWh}, \\
1,000 € / \mathrm{KW}_{\mathrm{e}}\end{array}$ & $\begin{array}{l}\text { Kear et al. [36], Abbes } \\
\text { et al. [1], Türker } \\
{[66 \text {, www.redtenergy.com }} \\
\text { [70] }\end{array}$ \\
\hline
\end{tabular}

Table 4: NSGA-II parameters for battery study

\begin{tabular}{ll}
\hline Population size & $N_{\text {pop }}=40$ \\
Selection & Binary tournament selection \\
Crossover & Intermediate crossover, Crossover fraction $=0.75$ \\
Mutation & Gaussian mutation, mutation fraction $=0.3$ \\
Stopping criteria & Maximum number of generations, $N_{g}=300$ \\
\hline
\end{tabular}

Hourly time steps were considered for the discretization of the model.

\subsubsection{Trade-off curve}

Figure 10 shows the non-dominated objective function values for 3 attempts. The average wall clock time from start to finish for the three parallelized runs was $183.5 \mathrm{~h}$ on a Linux based machine with eight 2.4 GHz Intel Xeon processors and 16 GB RAM. Each data point represents a different design. Moving from

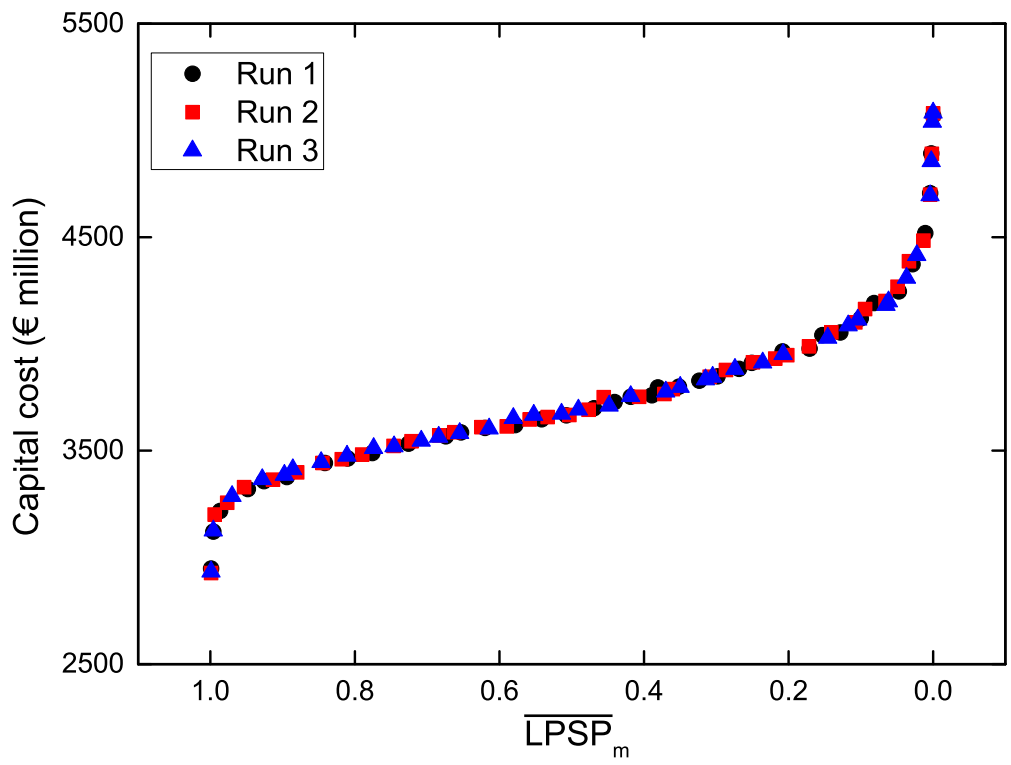

Figure 10: Approximations to Pareto front for base case from three attempts with NSGA-II 
Table 5: Objective values for minimum cost and maximum reliability designs for the three base case runs.

\begin{tabular}{crrr}
\hline & Min. cost design $\left(\overline{L P S P}_{m}=0.9992\right)$ \\
$(€$ million $)$ & $\begin{array}{r}\text { Max. reliability design }\left(\overline{L P S P}_{m}=0\right) \\
(€ \text { million })\end{array}$ & $\begin{array}{r}\text { Cost variation } \\
(\%)\end{array}$ \\
\hline Run 1 & 2948 & 5069 & 71.97 \\
Run 2 & 2927 & 5080 & 73.55 \\
Run 3 & 2933 & 5083 & 73.30 \\
\hline Variation & $2936 \pm 0.4 \%$ & $5077 \pm 0.2 \%$ & \\
\hline
\end{tabular}

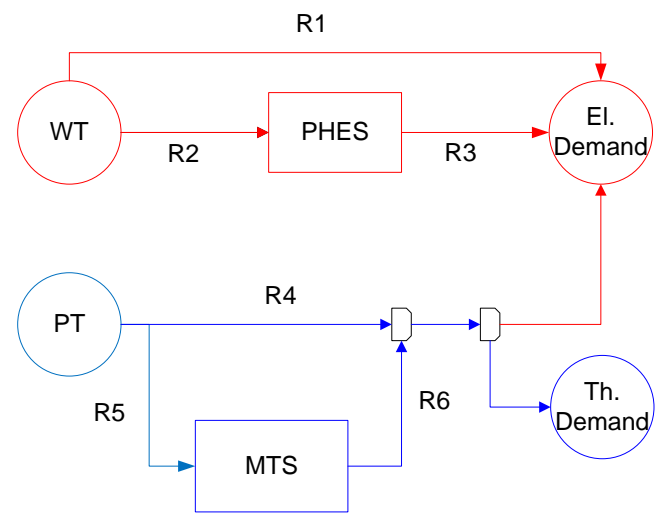

Figure 11: Optimal operating scheme for designs with possible energy routes for Canada case study after wind integration. The red and blue lines represent the electrical and thermal networks respectively.

left to right indicates increasing reliability. There is very little difference between the results of the three runs, giving a measure of confidence that set of non-dominated solutions have been identified well. Logically, the minimum cost solution involves doing nothing $\left(\overline{L P S P}_{m}=1, C C=0\right)$. The Pareto curve was seen to converge towards this trivial solution $\left(\overline{L P S P}_{m}=1, C C=0\right)$ on the left part of the Figure. However, that solution is not shown here as it provides no information. The minimum cost design is considered to be the next best solution; $\overline{\operatorname{LPSP}}_{m} \in[0,1)$.

Table 5 shows the costs of the minimum cost and maximum reliability designs for the three runs. The cost increase is between $72 \%$ and $74 \%$ in all three runs. The large cost increase observed for maximum reliability reflects the high variability in potential renewable input conditions at the location. The decision of which design $\bar{x}$ to choose (trading off between fossil fuel generation and renewable power) is left to the decision maker; see discussion in Amusat et al. [4].

\subsubsection{Energy system configuration}

Figure 11 shows the optimal energy system configuration in all three runs. It involves the installation of a power tower (PT) and wind turbines (WT) for generation, and tank storage (MTS) and pumped hydro (PHES) for storage. The WT and PHES systems satisfy electrical demands only, while the PT and MTS systems satisfy both electrical and thermal demands. This is a case where the PHES system has been selected 
Table 6: Characteristics of maximum reliability design from Run 3

\begin{tabular}{cccccc}
\hline$C_{P T}^{\text {gen }}$ & $C_{\text {wind }}^{\text {gen }}$ & $C_{M T S}^{s}$ & $C_{M T S}^{\text {out }}$ & $C_{P H E S}^{s}$ & $C_{P H E S}^{\text {out }}$ \\
\hline $4785 \mathrm{MW}_{\mathrm{th}}$ & $581 \mathrm{MW}_{\mathrm{e}}$ & $13784 \mathrm{MWh}$ & $188 \mathrm{MW}_{\mathrm{e}}$ & $437 \mathrm{MWh}$ & $21 \mathrm{MW}_{\mathrm{e}}$ \\
\hline
\end{tabular}

for electrical storage despite the implemented operating scheme prioritizing the AA-CAES for discharge. The selected operating scheme $(\overline{O P}=2)$ discharges the PHES before the MTS for power supply. This is logical: discharging less of the MTS for power generation ensures that thermal demands can be satisfied for longer. The order for electrical demand satisfaction is: $R 1>R 3>R 4>R 6$. The VRFB system, which is the only instantaneous response option, is not selected in the optimal configuration due to its high cost.

The decision to integrate wind and solar power for energy supply takes advantage of the seasonal anticorrelation in the time patterns of the renewable resources. The inverse relationship between the resources is evident from Figure 8: wind availability (and thus generation) increases between August and November and decreases between April and August; solar availability (and thus generation) is the opposite. Thus, combining the two resources provides balance to the energy system. This, combined with the poor solar availability at the location (especially in Winter), informed the decision to integrate the two generation options.

In order to analyze how the energy system designs obtained in the base case react to meet the electrical load of the mine, we will consider a single design from the Pareto front. In this case, maximum reliability design obtained in the third run is selected. The design is presented in Table 6 The rest of the analysis of the energy system configuration will be based on this design which is representative of all designs on the front.

\subsubsection{Energy mix for electrical load satisfaction}

Figure 12 shows the contributions of the different energy sources to the electrical output of the maximum reliability design. Direct energy supply from wind generation is the single largest contributor to the energy mix, supplying energy to meet more than $30 \%$ of the electrical load for the year in all the input scenarios. Very little of the energy generated from wind is stored as evidenced by the small PHES storage capacity. This suggests that wind generation was selected primarily for direct demand satisfaction, with the system taking advantage of its availability throughout day and night (unlike solar generation which is unavailable at night). Taking into account the PHES storage capacity and peak electrical load level, significant electricity dumping will occur whenever the wind turbine operates close to its nominal capacity. The WT/PHES systems are most active in the first half of the year with the highest power outputs occurring in April and May.

The thermal route (PT and MTS system) contributes over $60 \%$ of the total electricity required to meet load demands. It is most active for electricity supply in the summer months (June to August). 


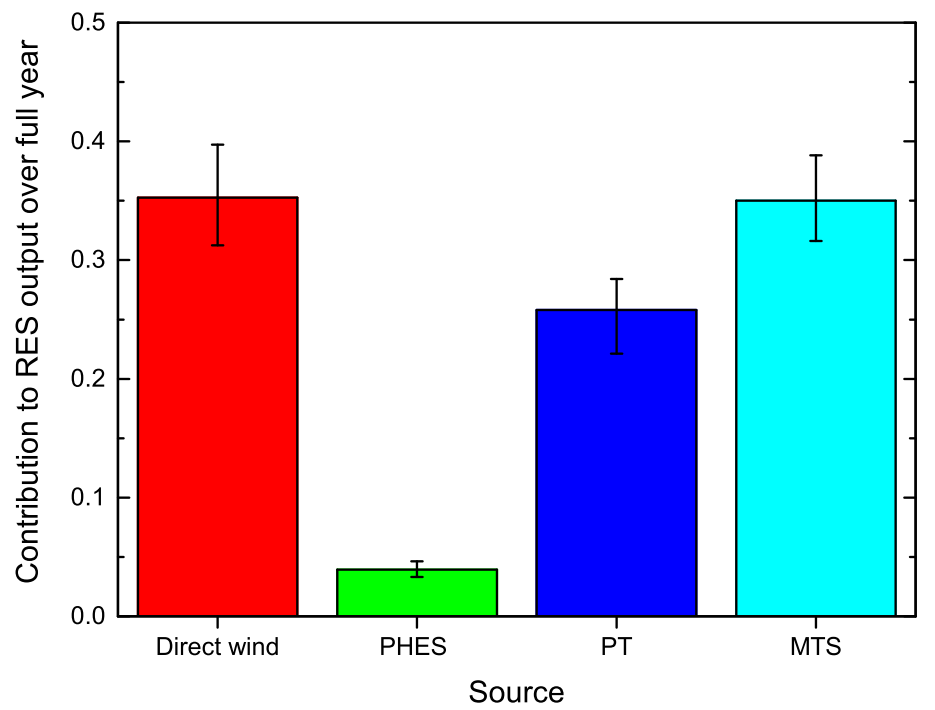

Figure 12: Average annual contribution of different energy sources to energy mix for electricity demand satisfaction. The error bars show the variation in the annual contribution over all 1,200 input scenarios due to renewables variability.

The error bars highlight the impact of variability on the contributions of the different sources to the RES output. As expected, years with good wind availability experience higher wind contribution to the energy mix, and vice versa. Direct wind contribution also experiences the highest variation over all 1,200 scenarios, deviating from the mean by up to $\pm 4.5 \%$.

\subsubsection{System operation}

To understand how the base case configuration handles the generation-load imbalance typically observed with renewables generation, we consider the behaviour of the maximum reliability design (Table 6) on a typical April day. April is considered because it is the month with the highest wind availability (see Fig. 8). Figure 13 shows the wind generation profile for the selected day. The wind turbine output exceeds the load demand for seven hours of the day, including a three-hour stretch around noon. At those times the plant requires no electricity from storage. The figure also highlights the intermitency challenge, with wind generation reducing dramatically in some hours. This is most noticeable around the 18th hour, where wind generation suddenly drops from $266 \mathrm{MW}_{\mathrm{e}}$ (more than enough to meet demand) to zero.

Figure 14 shows how the system output is influenced by the changes in wind generation level. When wind generation is in excess, the plant supplies all the energy directly from wind. When the level of wind generation drops, the system makes up the electricity shortfall from the PHES and thermal generation systems.

From the energy output profile for the day, the system configuration obtained for the base case would be considered infeasible if the times required to start-up the PHES and power block (Table 1) were taken into 


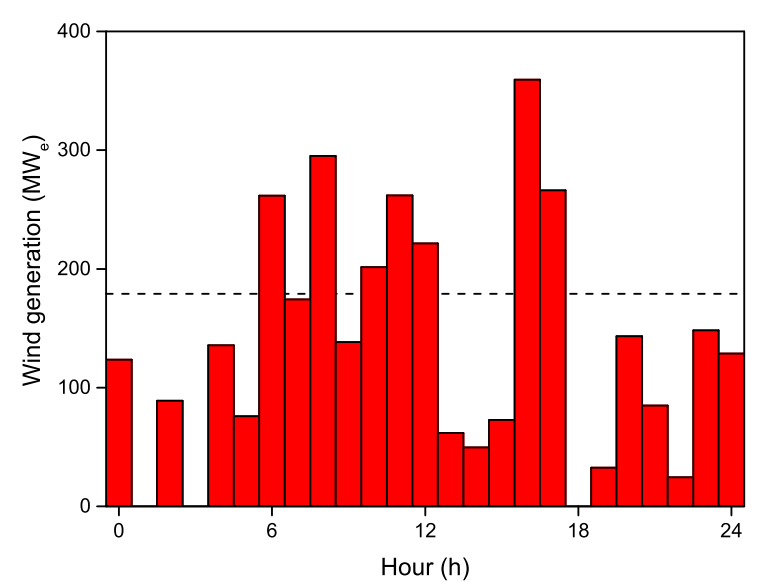

Figure 13: Wind generation profile of maximum reliability design on a typical April day. The broken black line shows the maximum electrical load on the day.

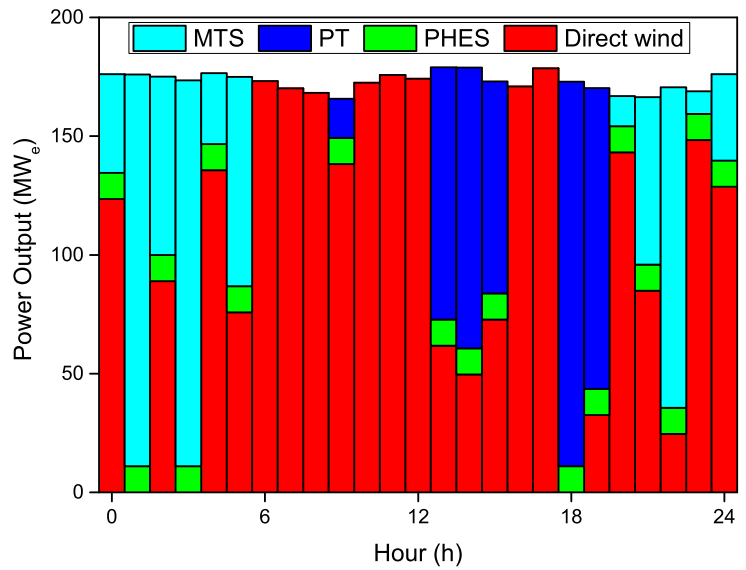

Figure 14: Corresponding power profile for the maximum reliability design on the April day. Transitions directly from wind to PHES and PT are observed.

account. For example, a power shortfall of $106 \mathrm{MW}_{\mathrm{e}}$ would occur for at least 15 minutes between $12 \mathrm{~h}$ and $13 \mathrm{~h}$ while the power block of the solar thermal system is switched on. In reality, the design would experience system failure at least three times on the April day (9h, 13h and 18h). The behaviour observed here highlights why storage response to dynamic variations in renewable generation cannot be ignored at the design stage in the sizing of renewable energy systems.

It is expected that the incorporation of time-dependent operational constraints based on the start-up times of the storage technologies will ensure that proposed energy system designs and configurations are well equipped to handle any potential intermittency in generation. This is investigated in the second case study.

\subsection{Incorporation of state-dependent operational constraints for storage}

In this case, the dispatch and operation of the storage systems account for the storage start-up time (Eqs. $2+40$ in the design process.

15-minute time steps were considered for the discretization of the entire model, corresponding to $t_{\text {start-up }}$ and the recommended minimum discharge period for electrochemical systems [28]. The smaller time steps allow us to monitor the system dynamics more accurately. However, it also means that evaluating the model for a full year (over 35,000 discrete steps) will require a significantly more time and memory.

The same renewable input scenarios considered in the base case are used, with the four 15-min intervals within each hour having the same value. The use of the same input data allows us to compare the results obtained from both case studies on the same basis. However, the data could also have been generated by making multiple predictions from the statistical models for each time step. For example, 15-min windspeed data could be generated by making four separate predictions from the Weibull distribution for each hour. 


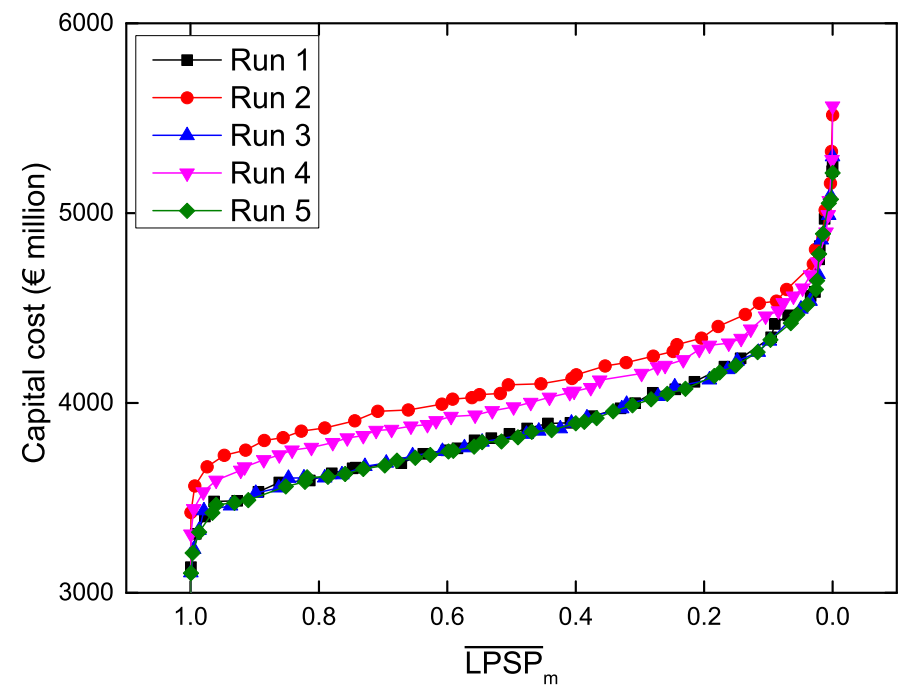

Figure 15: Approximations to Pareto front for battery-integrated system obtained in five attempts with NSGA-II. Three distinct fronts are obtained, with three of the runs (1,3 and 5) overlapping on the non-dominated front.

Table 7: Objective values for minimum cost and maximum reliability designs for the five runs. The fronts have been sorted by the cost of the maximum reliability design. All the cost values have been rounded up.

\begin{tabular}{|c|c|c|c|}
\hline Front & & $\begin{array}{r}\text { Min. cost design } \begin{array}{r}\left(\overline{L P S P}_{m}=0.9992\right) \\
(€ \text { million })\end{array}\end{array}$ & 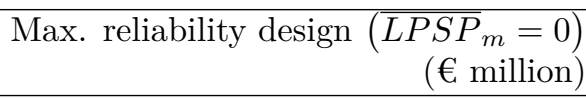 \\
\hline \multirow{3}{*}{1} & Run 5 & 3104 & $\begin{array}{ll}5212 \\
\end{array}$ \\
\hline & Run 3 & 3106 & 5237 \\
\hline & Run 1 & 3136 & 5245 \\
\hline 2 & Run 4 & 3309 & 5544 \\
\hline 3 & Run 2 & 3424 & 5517 \\
\hline
\end{tabular}

All other parameters are unchanged.

\subsubsection{Trade-off curve}

Figure 15 shows the solution fronts obtained from the 5 attempts. The average wall clock time from start to finish for the five parallelized runs was $1092 \mathrm{~h}$. Three different fronts have been obtained, with three of the runs converging to the same non-dominated front. Two of the runs (Runs 2 and 4) converged to sub-optimal solutions. Table 7 shows the objective values for the minimum cost and maximum reliability designs obtained in each of the five runs. A difference of $6 \%$ is observed in the costs of the most reliable designs obtained from the five runs. A comparison with the cost values from the base case (Table 5 indicates that higher costs will need to be incurred to obtain designs and/or configurations capable of operating feasibly in the aftermath of fluctuations in renewables power output.

The designs which make up each of the fronts have similar characteristics in terms of technology choices and are different from the designs on the other fronts. While the non-dominated front appears to have been identified, the presence of local fronts suggests that a larger population size or more generations may be 


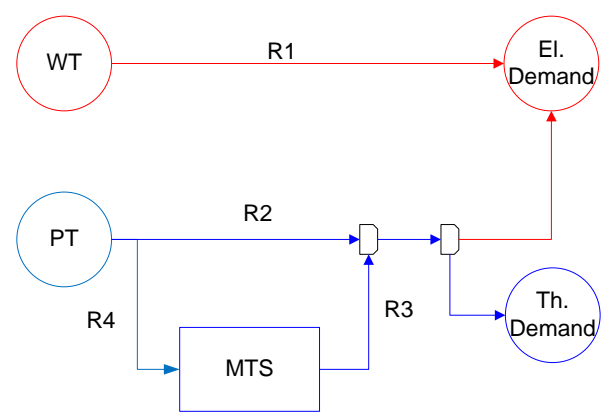

Figure 16: System configuration and operating scheme for designs. The red and blue lines represent the electrical and thermal networks respectively.

required for the problem. However, the presence of local fronts gives us the opportunity to explore different potential energy system configurations which address the intermittency challenge.

The characteristics of the solutions produced by two of the runs will be explored. First, the properties of one of the runs on the non-dominated front (run 5) will be discussed. This will be followed by an analysis of the characteristics of the designs on the first sub-optimal front (run 4). The focus will be on how intermittency impacts the technology choices, configuration and operating behaviour of the designs on those fronts.

\subsubsection{Characteristics of non-dominated front: Run 5}

System configuration. The system configuration involves the installation of a power tower (PT) and wind turbines (WT) for generation, and tank storage (MTS) as shown in Figure 16. Unlike the base case, no electrical storage option is selected. The WT system satisfies electrical demands only, while the PT and MTS systems satisfy both electrical and thermal demands.

The nominal wind turbine capacities of all the designs on the optimal front were $132 \mathrm{MW}_{\mathrm{e}}$ and $161 \mathrm{MW}_{\mathrm{e}}$, just below the minimum demand level of the plant $\left(164 \mathrm{MW}_{\mathrm{e}}\right)$. Thus, means that the wind turbines will generate no excess power: any power generated will be consumed immediately by the mine. This makes sense since no electrical storage option installed. The choice to reduce wind generation and eliminate the PHES system rather than install batteries highlights the high costs associated with battery storage.

Table 8 shows the maximum reliability design and the contributions of the different energy sources to the electrical output. The wind generation contribution to the energy mix is only about $11 \%$. This represents a significant reduction from its contribution in the base case (Fig. 12 where wind generation was the largest contributor to electrical load satisfaction. Thus, the system mitigates the impact of potential fluctuations in renewables generation simply by reducing its dependence on wind-related sources. The solar thermal system now contributes over $80 \%$ electricity required by the plant. 
Table 8: Characteristics of maximum reliability designs from run 5 (optimal run) and run 4 (non-optimal front). The first columns for each run shows the installed capacities of the various technologies, while the second column shows each technology's direct annual contribution to the energy mix for electrical demand satisfaction.

\begin{tabular}{|c|c|c|c|c|}
\hline \multirow{2}{*}{ Technology } & \multicolumn{2}{|r|}{ Run 5} & \multicolumn{2}{|r|}{ Run 4} \\
\hline & $\begin{array}{r}\text { Installed } \\
\text { capacities }\end{array}$ & $\begin{array}{r}\text { Annual (direct) } \\
\text { contribution to energy mix } \\
\text { for demand satisfaction }(\%)\end{array}$ & $\begin{array}{r}\text { Installed } \\
\text { capacities }\end{array}$ & $\begin{array}{r}\text { Annual (direct) } \\
\text { contribution to energy mix } \\
\text { for demand satisfaction }(\%)\end{array}$ \\
\hline WT & $156 \mathrm{MW}_{\mathrm{e}}$ & $11.29 \pm 1.72$ & $859 \mathrm{MW}_{\mathrm{e}}$ & $42.83 \pm 5.37$ \\
\hline $\mathrm{PT}$ & $5899 \mathrm{MW}_{\text {th }}$ & $39.81 \pm 2.17$ & $4368 \mathrm{MW}_{\text {th }}$ & $9.80 \pm 3.66$ \\
\hline PHES & - & - & $\begin{array}{l}503 \mathrm{MWh}, \\
22 \mathrm{MW}_{\mathrm{e}}\end{array}$ & $5.30 \pm 0.71$ \\
\hline AA-CAES & - & - & - & - \\
\hline MTS & $\begin{array}{r}18302 \mathrm{MWh}, \\
187 \mathrm{MW}_{\mathrm{e}}\end{array}$ & $48.90 \pm 2.16$ & $\begin{array}{r}11745 \mathrm{MWh} \\
187 \mathrm{MW}_{\mathrm{e}}\end{array}$ & $28.65 \pm 4.25$ \\
\hline VRFB & - & & $\begin{array}{l}\text { 431 MWh, } \\
215.5 \mathrm{MW}_{\mathrm{e}}^{*}\end{array}$ & $3.43 \pm 0.67$ \\
\hline
\end{tabular}

* Nominal DC capacity

System operation. To understand how the intermittency challenge is handled with this system configuration, we consider the behaviour of the maximum reliability design on the same April day considered in the base case. From the installed wind turbine capacity $\left(156 \mathrm{MW}_{\mathrm{e}}\right)$, it is clear that the wind output will never be sufficient to meet the load demands of the plant. The peak generation from wind for the selected April day is $96 \mathrm{MW}_{\mathrm{e}}$, less than the load demand at any point during the day. Thus, the plant is able to absorb all the wind power generated. During the day, wind power is supported by power generated from the power tower output to meet the demands of the mine. At night, the MTS system supports the wind output. At least one of the PT or MTS systems is always required; the power block is always in operation. This ensures that any sudden drop in wind power output can easily be compensated for. Thus, the energy system configuration takes advantage of the integrated nature of the solar thermal system and is dependent on the assumption of instantaneous ramping. The same operating behaviour can be expected for all designs on this solution front since the wind turbine capacity is roughly the same for all the designs (between $132 \mathrm{MW}_{\mathrm{e}}$ and $161 \mathrm{MW}_{\mathrm{e}}$ ). It is important to note that with this energy system configuration, the maximum allowable wind contribution to the energy mix is dependent on the power demand level of the mine: any significant reduction in the power demand (for example, due to equipment downtime) must be accompanied by a corresponding reduction in the online wind power generation capacity. This is necessary to ensure that the maximum potential wind power output remains insufficient to meet the full power demands of the mine.

\subsubsection{Characteristics of first dominated front: Run 4}




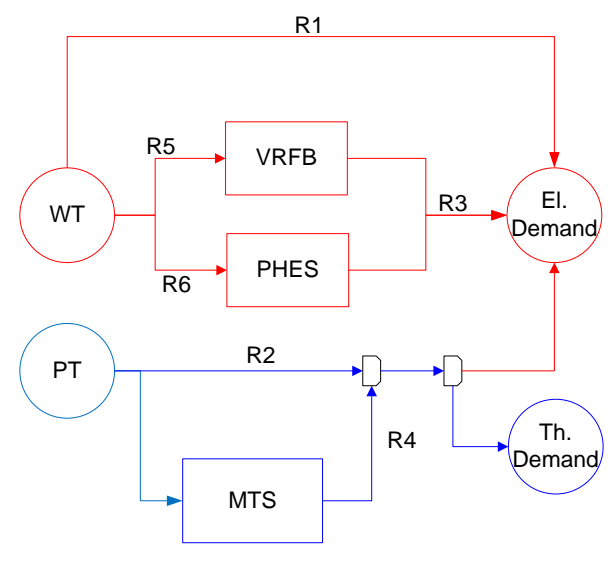

Figure 17: System configuration and operating scheme for designs. The red and blue lines represent the electrical and thermal networks respectively.

System configuration. The system design involves the installation of a power tower (PT) and wind turbines (WT) for generation, and three different storage options as shown in Figure 17 Batteries have been installed to smoothen out the intermittency of wind generation. The WT, VRFB and PHES systems meet power demands only, while the PT and MTS meet both electrical and heat loads. Priority is given to the battery system (R5) during charging.

The maximum reliability design, shown in Table 8 , will be considered for analysis of the energy system configuration. The installed wind turbine capacity is more than four times the peak load; direct generation from wind will be sufficient to meet demand in time periods in which the wind turbines are able to operate at more than $25 \%$ of their nominal capacities. The design incorporates two hours of battery storage. This allows the system roughly eight 15-minute discharges before the battery is emptied. The rest of the analysis of the energy system configuration will be based on this design.

Table 8 also shows the contributions of the different energy sources to the electrical output of the maximum reliability design. Direct energy supply from wind generation is the single largest contributor to the energy mix, supplying between $39 \%$ and $48 \%$ of the electrical energy required for load satisfaction. Again, the electrical storage systems (PHES and VRFB) combine to provide less than $10 \%$ of the annual electricity supply, showing that wind generation is selected primarily for direct demand satisfaction. The system depends on the thermal options (PT/MTS) to backup wind generation.

Operating behaviour. We consider the operating behaviour of the maximum reliability design on the same April day considered in the previous cases. From Figure 18 , we see that the wind output exceeds the demand level in 13 hours of the day. At those hours, the mine is run purely on wind generation. The excess electricity generation in those hours is either sent to storage or dumped. The battery system provides temporary power 


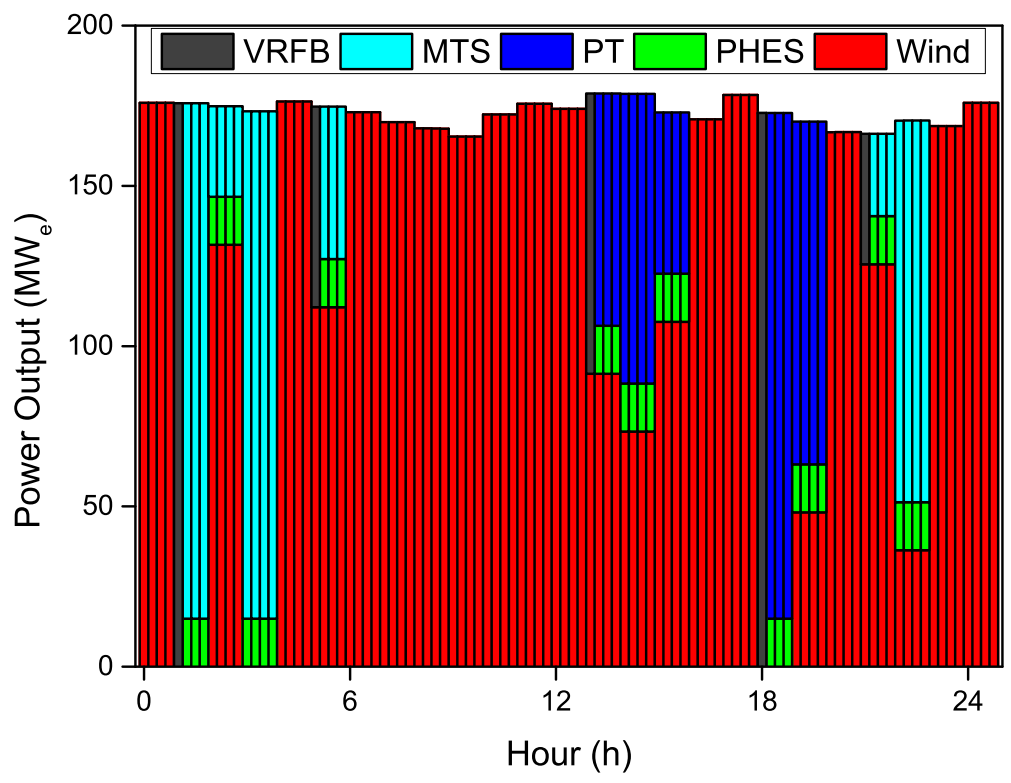

Figure 18: Power profile for the maximum reliability design on a typical April day. The VRFB system provides power for the 15 minutes immediately after wind generation reduction.

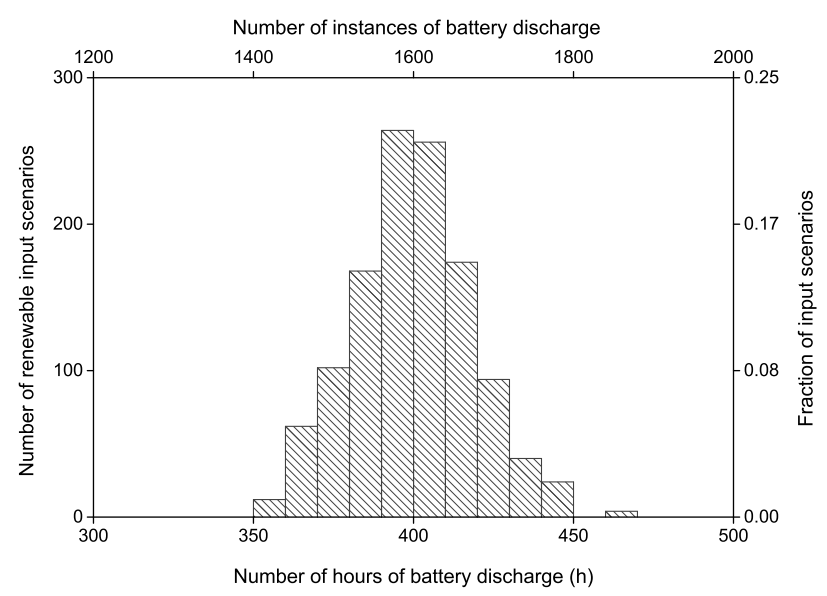

Figure 19: Battery discharge time over all renewable input scenarios.

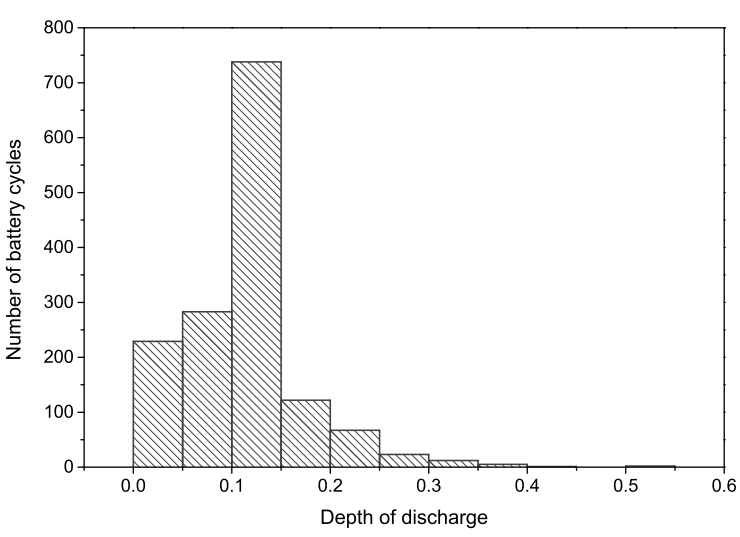

Figure 20: Battery DOD distribution probability for selected sample scenario

for 15 minutes when insufficient wind generation suddenly occurs. This gives the other systems sufficient time to start up. The battery system is only required in five time periods (equivalent to $1.25 \mathrm{~h}$ ) on the day. Wind power variations below the demand level are managed by increasing or decreasing the power outputs of the other power supply options.

Battery deployment. Figure 19 is a distribution showing how frequently the battery system of the maximum reliability design was used in the 1,200 renewable input scenarios considered. On the average, the battery discharges for about $400 \mathrm{~h}(4.6 \%)$ each year. The battery completes between 1,200 and 2,000 cycles each year, meaning that the battery is required between 4-6 times per day on the average. However, most of the 
cycles are partial, with the battery most frequently discharged by only 10-15\%. A typical example of the battery's depth-of-discharge distribution is shown in Figure 20

To evaluate the battery cycle lifetime, the number of full battery cycles is required. This can be evaluated from the partial cycle information available using the equivalent full cycle (EFC) concept [5]. Applying the approach to the partial cycle information shown in Figure 20 reveals that the battery operates for the equivalent of 207 full cycles in the year. Given that the typical cycle lifetime of Vanadium RFBs is over 12,000 cycles [40], the battery will be able to operate at this rate for over 50 years before it needs to be replaced. The battery system is therefore likely to outlive the mine.

\subsection{Summary of results}

From the results of the base case study (particularly Figure 14), designing integrated renewable energy systems without accounting for the response of storage technologies to sudden fluctuations in renewables generation can lead to the design configurations which are inoperable in reality.

The results presented in Section 8.2 show that the incorporation of operational constraints based on the response characteristics of the storage systems can be useful in ensuring that only feasible energy system configurations are obtained. Two approaches which may be employed to ensure that fluctuations in renewables output do not lead to failure of the renewable energy system are demonstrated in the results.

The first approach involves reducing the dependence of the energy system on intermittent resources. With this method, the energy system output is never solely dependent on an intermittent resource: a more reliable resource capable of meeting the entire load always contributes to the output of the energy system. This ensures that when the intermittent resource fails, the reliable source (already online) only needs to be ramped up to supply more power. This approach is demonstrated here by the designs on the first solution front (Section 8.2.2. In those designs, the system reduced its dependence on wind generation and increased its dependence on solar thermal generation which is the more reliable power source in this case. However, the reliable resource may also be more conventional generation options like diesel or gas generators.

The designs obtained on the second front (Section 8.2.3) demonstrate a different approach: the impact of renewables intermittency is mitigated by ensuring that at least one storage option which can react instantaneously to fluctuations in renewables generation is incorporated into the energy system design. Unlike the approach in the first case which was based on limiting the contribution of the intermittent resource, this approach focuses on modifying storage rather than generation. The storage options are selected and/or combined in such a way as to ensure that any periods of sudden power failure are catered for. The battery 
system was selected as it is the only instantaneous option in the superstructure. However, where more than one instantaneous storage option is made available, designing the energy system would involve optimizing the choice of the instant response storage option. The results obtained demonstrate how different storage options can be combined optimally to make the best use of their peculiar characteristics.

The results demonstrate that accounting for intermittency will incur extra cost, impact technology choices and may affect the system configuration. However, despite the intermittency of the wind resource, designs obtained in all the runs integrate solar and wind resources for power generation. This suggests that the advantages provided by solar and wind integration outweigh the challenges associated with wind generation.

\section{Conclusion}

An optimization-based methodology for the sizing of hybrid renewable energy systems integrating multiple generation and storage technologies for thermal and electrical load satisfaction has been presented. The methodology shows how both renewables variability and the fluctuating nature of renewables generation can be accounted for at the design stage in energy system sizing. A reliability measure which takes into the system performance under different input conditions is used to account for climate-based variability in renewables availability. The start-up times of the storage technologies are incorporated into the design problem to ensure that only feasible designs are generated at the design stage. The results demonstrate two approaches for mitigating the impact of renewables intermittency on the energy system output and show that accounting for intermittency will have an impact on the cost and configuration of energy system designs. The methodology presented is applicable to any location, can be extended to incorporate other generation and storage technologies, and provides the decision maker with information about a number of feasible designs and configurations based on which sizing decisions can be made. It ensures that the storage options are able to provide the main functions required for smooth and uninterrupted power from renewables: load shifting, standby reserve and response to renewable power fluctuations.

\section{Acknowledgments}

The authors would like to acknowledge the funding provided by the Nigerian government through the presidential scholarship for innovation and development (PRESSID) scheme for this research. P.R. Shearing acknowledges funding from the Royal Academy of Engineering. 


\section{Nomenclature}

$\alpha$

$\bar{X}$

$\bar{x}_{n}$

$\beta$

$\eta_{b a t, c h}$

$\eta_{\text {bat }, \text { dis }}$

$\eta_{i n v, a c-d c}$

$\eta_{i n v, d c-a c}$

$\overline{\operatorname{LPSP}}_{m}$

$\overline{O P}$

$\dot{D}^{e l}(t)$

$\dot{D}^{t h}(t)$

$\dot{E}^{\text {load }}(t)$

$\dot{E}^{R E S}(t$

$\dot{E}_{\text {dumped }}(t)$

$\dot{E}_{j}^{i n}(t)$

$\dot{E}_{P V}^{g e n}(t)$

$\dot{E}_{\text {wind }}^{\text {gen }}(t)$

$\dot{G}^{D N I}(t)$

$\dot{G}^{t o t}(t)$

heating

$Q_{A A-C A E S}$

$\dot{Q}_{M T S}^{\text {heating }}(t)$

$\dot{Q}^{R E S}(t)$
Scale parameter for Weibull distribution $[\mathrm{m} / \mathrm{s}]$

set of non-dominated designs

nth non-dominated design

Shape parameter for Weibull distribution

Battery charging efficiency, unitless

Battery discharge efficiency, unitless

AC-DC inverter efficiency, unitless

DC-AC inverter efficiency, unitless

Modified loss of power probability, unitless

Discharge operating scheme number

Instantaneous electrical demand of the mine [MW]

Instantaneous thermal demand of the mine[MW]

Total electrical load, made up of mine demand and parasitic requirements [MW]

Renewable energy system gross electrical output [MW]

Rejected electrical energy [MW]

Energy input into storage option $j[\mathrm{MW}]$

Electrical energy output from PV [MW]

Electrical energy output from wind generator [MW]

Instantaneous direct normal irradiance $\left[\mathrm{W} / \mathrm{m}^{2}\right]$

Instantaneous global horizontal irradiance $\left[\mathrm{W} / \mathrm{m}^{2}\right]$

Heat to plant from AA-CAES system [MW]

Combined heat to plant from power tower and MTS systems [MW]

Renewable energy system gross thermal output [MW] 


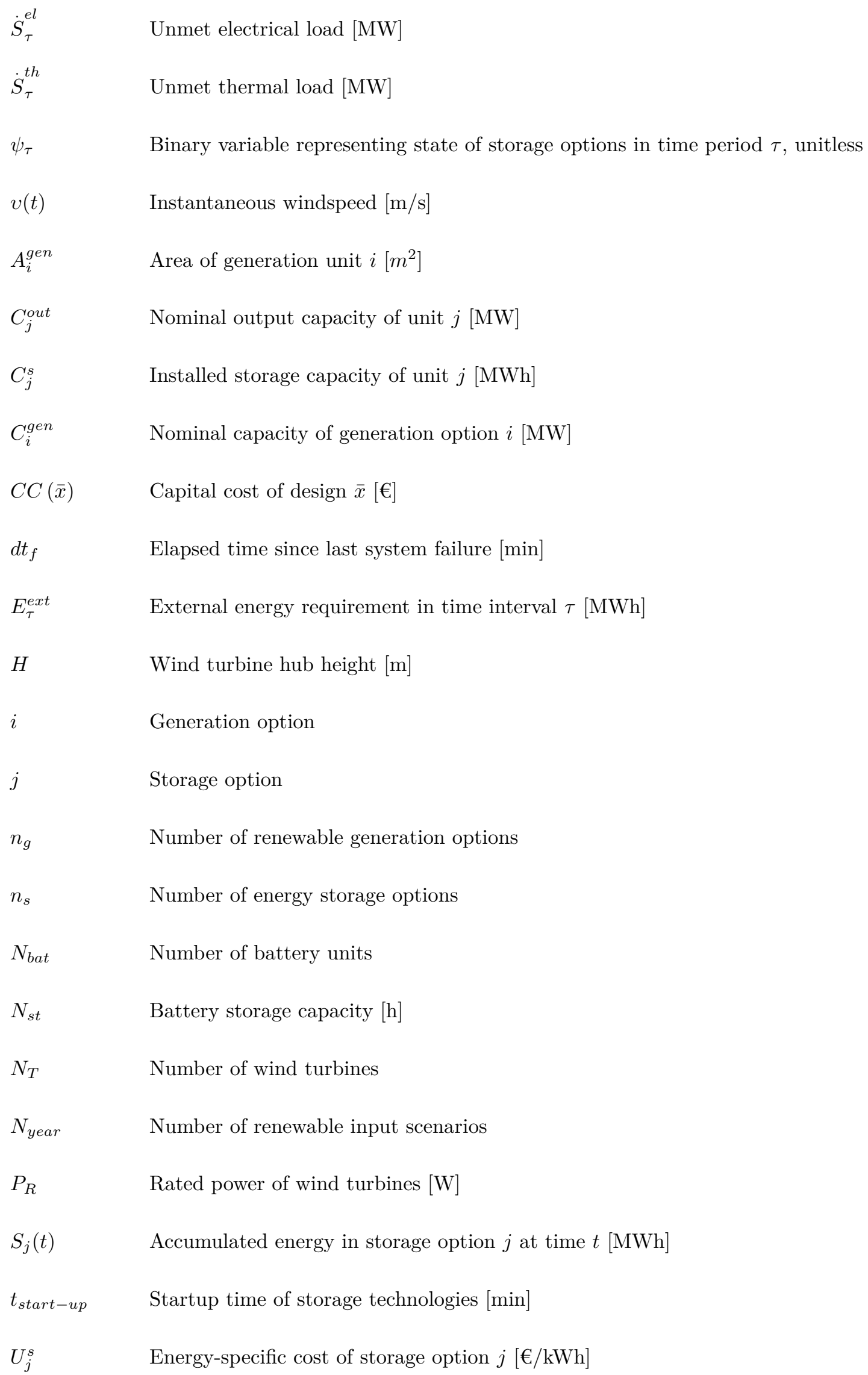


$U_{i}^{g e n}$

$U_{i}^{\text {out }}$

EE

$\kappa$
Unit cost of generation option $i\left[€ / \mathrm{m}^{2}\right]$

Capacity-specific cost of storage option $j\left[€_{/} / \mathrm{kW}_{\mathrm{e}}\right]$

Total external energy requirement [MWh]

Rate of battery self-discharge [\%/day] 


\section{References}

[1] Abbes, D., Martinez, A., Champenois, G., Apr 2014. Life cycle cost, embodied energy and loss of power supply probability for the optimal design of hybrid power systems. Mathematics and Computers in Simulation $98,46-62$.

URL http://dx.doi.org/10.1016/j.matcom.2013.05.004

[2] Al-Shamma'a, A., Addoweesh, K., 2014. Techno-economic optimization of hybrid power system using genetic algorithm. International Journal of Energy Research 38, 1608-1623.

URL http://www.scopus.com/inward/record.url?eid=2-s2.0-84908357430\&partnerID=40\&md5= $337663 e 1 d d 383316 c 5 c 3 e 8 f 0 d 841 c 55 f$

[3] Amusat, O. O., Shearing, P. R., Fraga, E. S., Dec 2016. Optimal integrated energy systems design incorporating variable renewable energy sources. Computers \& Chemical Engineering 95, 21-37.

URL http://dx.doi.org/10.1016/j.compchemeng.2016.08.007

[4] Amusat, O. O., Shearing, P. R., Fraga, E. S., Aug 2017. On the design of complex energy systems: Accounting for renewables variability in systems sizing. Computers \& Chemical Engineering 103, 103115.

URL http://dx.doi.org/10.1016/j.compchemeng.2017.03.010

[5] Ashari, M., Nayar, C., May 1999. An optimum dispatch strategy using set points for a photovoltaic (PV)-diesel-battery hybrid power system. Solar Energy 66 (1), 1-9.

URL http://dx.doi .org/10.1016/S0038-092X(99)00016-X

[6] Atwa, Y., El-Saadany, E., Guise, A.-C., Feb 2010. Supply adequacy assessment of distribution system including wind-based dg during different modes of operation. IEEE Transactions on Power Systems $25(1), 78-86$.

URL http://dx.doi.org/10.1109/TPWRS.2009.2030282

[7] Belfkira, R., Zhang, L., Barakat, G., Jan 2011. Optimal sizing study of hybrid wind/PV/diesel power generation unit. Solar Energy 85 (1), 100-110.

URL http://dx.doi.org/10.1016/j.solener.2010.10.018

[8] Bermudez, J., Ruisanchez, E., Arenillas, A., Moreno, A., Menendez, J., Feb 2014. New concept for energy storage: Microwave-induced carbon gasification with CO2. Energy Conversion and Management $78,559-564$.

URL http://dx.doi.org/10.1016/j.enconman.2013.11.021 
[9] Borowy, B., Salameh, Z., Jun 1996. Methodology for optimally sizing the combination of a battery bank and PV array in a wind/PV hybrid system. IEEE Transactions on Energy Conversion 11 (2), 367-375. URL http://dx.doi.org/10.1109/60.507648

[10] Brus, D., de Gruijter, J., Oct 1997. Random sampling or geostatistical modelling? choosing between design-based and model-based sampling strategies for soil (with discussion). Geoderma 80 (1-2), 1-44. URL http://dx.doi .org/10.1016/S0016-7061(97)00072-4

[11] Bueno, C., Carta, J., Mar 2005. Technical-economic analysis of wind-powered pumped hydrostorage systems. part i: model development. Solar Energy 78 (3), 382-395.

URL http://dx.doi.org/10.1016/j.solener.2004.08.006

[12] Bueno, C., Carta, J., Mar 2005. Technical-economic analysis of wind-powered pumped hydrostorage systems. part ii: model application to the island of el hierro. Solar Energy 78 (3), 396-405.

URL http://dx.doi.org/10.1016/j.solener.2004.08.007

[13] Chauhan, A., Saini, R., Oct 2014. A review on integrated renewable energy system based power generation for stand-alone applications: Configurations, storage options, sizing methodologies and control. Renewable and Sustainable Energy Reviews 38, 99-120.

URL http://dx.doi.org/10.1016/j.rser.2014.05.079

[14] Chen, H., Cong, T., Yang, W., Tan, C., Li, Y., Ding, Y., 2009. Progress in electrical energy storage system: A critical review. Progress in Natural Science 19 (3), 291-312.

URL http://www.scopus.com/inward/record.url?eid=2-s2.0-63749132596\&partnerID=40\&md5= $0441 \mathrm{bdd} 26157902684 \mathrm{~b} 5648 \mathrm{~b} 48 \mathrm{~d} 36186$

[15] Connolly, D., Lund, H., Mathiesen, B., Pican, E., Leahy, M., Jul 2012. The technical and economic implications of integrating fluctuating renewable energy using energy storage. Renewable Energy 43, $47-60$.

URL http://dx.doi.org/10.1016/j.renene.2011.11.003

[16] Deb, K., Pratap, A., Agarwal, S., Meyarivan, T., Apr 2002. A fast and elitist multiobjective genetic algorithm: Nsga-ii. IEEE Trans. Evol. Computat. 6 (2), 182-197.

URL http://dx.doi .org/10.1109/4235.996017

[17] Denholm, P., Mehos, M., 2011. Enabling greater penetration of solar power via the use of csp with thermal energy storage. Tech. rep., National Renewable Energy Laboratory (NREL), Golden, CO. 
[18] Denholm, P., Wan, Y., Hummon, M., Mehos, M., 2013. Analysis of concentrating solar power with thermal energy storage in a california $33 \%$ renewable scenario. Tech. rep., National Renewable Energy Laboratory (NREL), Golden, CO.

[19] Department of Environmental and Natural Resources, Government of Canada, 2016. Past weather and climate: Historical Data. [Online]. Available at: http://climate.weather.gc.ca/historical_data/ search_historic_data_e.html, accessed 19 July 2015.

[20] Diaf, S., Belhamel, M., Haddadi, M., Louche, A., Feb. 2008. Technical and economic assessment of hybrid photovoltaic/wind system with battery storage in corsica island. Energy Policy 36 (2), 743-754. URL http://www.sciencedirect.com/science/article/pii/S0301421507004788

[21] Erdinc, O., Uzunoglu, M., Apr 2012. Optimum design of hybrid renewable energy systems: Overview of different approaches. Renewable and Sustainable Energy Reviews 16 (3), 1412-1425.

URL http://dx.doi.org/10.1016/j.rser.2011.11.011

[22] Evans, A., Strezov, V., Evans, T. J., Aug 2012. Assessment of utility energy storage options for increased renewable energy penetration. Renewable and Sustainable Energy Reviews 16 (6), 4141-4147.

URL http://dx.doi.org/10.1016/j.rser.2012.03.048

[23] Fares, R. L., Meyers, J. P., Webber, M. E., Jan 2014. A dynamic model-based estimate of the value of a vanadium redox flow battery for frequency regulation in texas. Applied Energy 113, 189-198.

URL http://dx.doi.org/10.1016/j.apenergy .2013.07.025

[24] Flueckiger, S. M., Iverson, B. D., Garimella, S. V., Pacheco, J. E., Jan 2014. System-level simulation of a solar power tower plant with thermocline thermal energy storage. Applied Energy 113, 86-96.

URL http://dx.doi.org/10.1016/j.apenergy.2013.07.004

[25] Garcia, A., Torres, J., Prieto, E., de Francisco, A., Feb 1998. Fitting wind speed distributions: a case study. Solar Energy 62 (2), 139-144.

URL http://dx.doi.org/10.1016/S0038-092X(97)00116-3

[26] Gooding, P., Makram, E., Hadidi, R., Mar 12-15 2013. Islanding effects in distributed generation with probability analysis. In: Power Systems Conference (PSC 2013).

URL http://rtpis .org/psc13/files/PSC2013_final_1358372696.pdf

[27] Gooding, P., Makram, E., Hadidi, R., Feb 2014. Probability analysis of distributed generation for island scenarios utilizing carolinas data. Electric Power Systems Research 107, 125-132.

URL http://dx.doi.org/10.1016/j.epsr.2013.09.012 
[28] Ibrahim, H., Ilinca, A., Perron, J., 2008. Energy storage systems - characteristics and comparisons. Renewable and Sustainable Energy Reviews 12 (5), 1221 - 1250.

URL http://www.sciencedirect.com/science/article/pii/S1364032107000238

[29] International Energy Agency, Nov 2014. Technology roadmap: Energy storage. Tech. rep., International Energy Agency, [Online]. Available at: http://www.iea.org/publications/ freepublications/publication/WorldEnergyOutlook2016ExecutiveSummaryEnglish.pdf (Accessed 02 December 2016).

[30] International Energy Agency, 2016. Key world energy statistics 2016. Tech. rep., International Energy Agency, [Online].Available at: http://www.iea.org/publications/freepublications/ publication/KeyWorld2016.pdf (Accessed 02 December 2016).

[31] International Energy Agency, 2016. World energy outlook 2016: Executive summary. Tech. rep., International Energy Agency, [Online].Available at: http://www.iea.org/publications/freepublications/ publication/world-energy-outlook-2016---executive-summary---english-version.html

(Accessed 02 December 2016).

[32] Kamel, S., Jun 2005. The economics of hybrid power systems for sustainable desert agriculture in egypt. Energy 30 (8), 1271-1281.

URL http://dx.doi.org/10.1016/j.energy .2004.02.004

[33] Kaplani, E., Kaplanis, S., Sep 2012. A stochastic simulation model for reliable PV system sizing providing for solar radiation fluctuations. Applied Energy 97, 970-981.

URL http://dx.doi .org/10.1016/j . apenergy . 2011.12.016

[34] Karaki, S., Chedid, R., Ramadan, R., 1999. Probabilistic performance assessment of autonomous solarwind energy conversion systems. IEEE Transactions on Energy Conversion 14 (3), 766-772.

URL http://dx.doi.org/10.1109/60.790949

[35] Kavasseri, R. G., Seetharaman, K., May 2009. Day-ahead wind speed forecasting using f-arima models. Renewable Energy 34 (5), 1388-1393.

URL http://dx.doi.org/10.1016/j.renene.2008.09.006

[36] Kear, G., Shah, A. A., Walsh, F. C., May 2011. Development of the all-vanadium redox flow battery for energy storage: a review of technological, financial and policy aspects. Int. J. Energy Res. 36 (11), $1105-1120$.

URL http://dx.doi.org/10.1002/er.1863 
[37] Khatod, D. K., Pant, V., Sharma, J., Jun 2010. Analytical approach for well-being assessment of small autonomous power systems with solar and wind energy sources. IEEE Transactions on Energy Conversion $25(2), 535-545$.

URL http://dx.doi.org/10.1109/TEC.2009.2033881

[38] Kloess, M., May 2012. Electric storage technologies for the future power system - an economic assessment. 2012 9th International Conference on the European Energy Market.

URL http://dx.doi.org/10.1109/EEM.2012.6254729

[39] Louche, A., Notton, G., Poggi, P., Simonnot, G., 1991. Correlations for direct normal and global horizontal irradiation on a french mediterranean site. Solar Energy 46 (4), 261-266.

URL http://dx.doi.org/10.1016/0038-092X(91)90072-5

[40] Luo, X., Wang, J., Dooner, M., Clarke, J., Jan 2015. Overview of current development in electrical energy storage technologies and the application potential in power system operation. Applied Energy $137,511-536$.

URL http://dx.doi.org/10.1016/j.apenergy .2014.09.081

[41] Madaeni, S. H., Sioshansi, R., Denholm, P., Feb 2012. How thermal energy storage enhances the economic viability of concentrating solar power. Proceedings of the IEEE 100 (2), 335-347.

URL http://dx.doi.org/10.1109/JPROC.2011.2144950

[42] Mahesh, A., Sandhu, K. S., Dec 2015. Hybrid wind/photovoltaic energy system developments: Critical review and findings. Renewable and Sustainable Energy Reviews 52, 1135-1147.

URL http://dx.doi.org/10.1016/j.rser.2015.08.008

[43] Maleki, A., Askarzadeh, A., Jun 2014. Comparative study of artificial intelligence techniques for sizing of a hydrogen-based stand-alone photovoltaic/wind hybrid system. International Journal of Hydrogen Energy 39 (19), 9973-9984.

URL http://dx.doi.org/10.1016/j.ijhydene.2014.04.147

[44] Masters, G. M., 2013. Renewable and efficient electric power systems. John Wiley \& Sons.

[45] McIvor, A., 2010. Energy in mining. Cleantech (special edition fuel cells) 5, 16-19.

[46] Mckay, M. D., Beckman, R. J., Conover, W. J., Feb 2000. A comparison of three methods for selecting values of input variables in the analysis of output from a computer code. Technometrics 42 (1), 55-61. URL http://dx.doi .org/10.1080/00401706.2000.10485979 
[47] Merei, G., Berger, C., Sauer, D. U., Nov 2013. Optimization of an off-grid hybrid PV-wind-diesel system with different battery technologies using genetic algorithm. Solar Energy 97, 460-473.

URL http://dx.doi.org/10.1016/j.solener.2013.08.016

[48] Moore, M. A., 2013. A base case design and capital cost analysis of an all vanadium redox-flow battery. Master's thesis, University of Tennessee.

URL http://trace.tennessee.edu/utk_gradthes/2441

[49] National Renewable Energy Laboratory, 2015. National Solar Radiation Data Base. [Online]. Available at: http://rredc.nrel.gov/solar/old_data/nsrdb/, Accessed 30 April 2014.

[50] National Renewable Energy Laboratory, NREL, 2012. Cost and performance data for power generation technologies. Tech. rep., prepared by Black \& Veatch.

URL http://bv.com/docs/reports-studies/nrel-cost-report.pdf

[51] Organization of the Petroleum Exporting Countries, October 2016. 2016 OPEC World Oil Outlook. [Online]. Available from: http://www.opec.org/, accessed 24 January 2017.

[52] Paliwal, P., Patidar, N., Nema, R., Mar 2014. Determination of reliability constrained optimal resource mix for an autonomous hybrid power system using particle swarm optimization. Renewable Energy 63, 194-204.

URL http://dx.doi.org/10.1016/j.renene.2013.09.003

[53] Paraszczak, J., Fytas, K., 23-30 Mar 2012. Renewable energy sources - a promising opportunity for remote mine sites? In: International Conference on Renewable Energies and Power Quality (ICREPQ 12). Santiago de Compostela (Spain).

[54] Pearson, K., 1916. Mathematical contributions to the theory of evolution. xix. second supplement to a memoir on skew variation. Philosophical Transactions of the Royal Society of London A: Mathematical, Physical and Engineering Sciences 216 (538-548), 429-457.

[55] Pellegrino, J., Margolis, N., Justiniano, M., Miller, M., Thedki, A., 2004. Energy use, loss and opportunities analysis: Us manufacturing and mining. US Department of Energy.

[56] Perera, A., Attalage, R., Perera, K., Dassanayake, V., Jun 2013. Designing standalone hybrid energy systems minimizing initial investment, life cycle cost and pollutant emission. Energy 54, 220-230.

URL http://dx.doi.org/10.1016/j .energy .2013.03.028 
[57] Powell, K. M., Edgar, T. F., 2012. Modeling and control of a solar thermal power plant with thermal energy storage. Chemical Engineering Science 71 (0), 138 - 145.

URL http://www.sciencedirect.com/science/article/pii/S0009250911008657

[58] Root, M., November 2010. The Tab battery book: an in-depth guide to construction, design and use. McGraw-Hill/Tab Electronics.

URL https://www.dawsonera.com:443/abstract/9780071739917

[59] Song, L., 2011. NGPM - An NSGA-II program in Matlab v1.4. Aerospace structural dynamics research laboratory, College of Astronautics, Northwestern Polytechnical University, China.

URL http://uk.mathworks.com/matlabcentral/fileexchange/31166-ngpm-a-nsga-ii-programin-matlab-v1-4

[60] Tegani, I., Aboubou, A., Ayad, M., Becherif, M., Saadi, R., Kraa, O., 2014. Optimal sizing design and energy management of stand-alone photovoltaic/wind generator systems. Energy Procedia 50, 163-170. URL http://dx.doi.org/10.1016/j.egypro.2014.06.020

[61] The Wind Power, 2016. Manufacturers and turbines: NEG Micon NM44/750. [Online], Accessed 19 August 2015 .

URL http://www.thewindpower.net/turbine_en_236_neg-micon_750.php

[62] Tina, G., Gagliano, S., Feb 2011. Probabilistic analysis of weather data for a hybrid solar/wind energy system. Int. J. Energy Res. 35 (3), 221-232.

URL http://dx .doi .org/10.1002/er.1686

[63] Tina, G., Gagliano, S., Raiti, S., May 2006. Hybrid solar/wind power system probabilistic modelling for long-term performance assessment. Solar Energy 80 (5), 578-588.

URL http://dx.doi.org/10.1016/j.solener.2005.03.013

[64] Tito, S., Lie, T., Anderson, T., Oct 2016. Optimal sizing of a wind-photovoltaic-battery hybrid renewable energy system considering socio-demographic factors. Solar Energy 136, 525-532.

URL http://dx.doi.org/10.1016/j.solener.2016.07.036

[65] Tuohy, A., O'Malley, M., Jul 2009. Impact of pumped storage on power systems with increasing wind penetration. 2009 IEEE Power \& Energy Society General Meeting.

URL http://dx.doi.org/10.1109/PES.2009.5275839 
[66] Türker, B., December 2014. Modeling and utilizing a vanadium redox flow battery for easier grid and market integration of wind power. Ph.D. thesis, Staats-und Universitätsbibliothek Bremen.

URL http://elib.suub.uni-bremen.de/peid/D00104249.html

[67] US Department of Energy, 2007. U.S. mining industry energy bandwidth study. Tech. rep., prepared by BCS Inc.

[68] Weisser, D., Garcia, R. S., Jul 2005. Instantaneous wind energy penetration in isolated electricity grids: concepts and review. Renewable Energy 30 (8), 1299-1308.

URL http://dx.doi.org/10.1016/j.renene.2004.10.002

[69] Wilson, S. D., Samuel, J., Simmonds, G., 2013. An energy storage system for the scottish isle of gigha. In: Power in Unity: a Whole System Approach, IET Conference on. pp. 1-5.

[70] www.redtenergy.com, ???? Module Datasheet for redT 5-20 energy storage system: 5-20 preliminary specifications. [Online]. Available at: http://www.redtenergy.com/files/5-20\%20GEN2\%20Prelim\% 20Datasheet $\% 20-\% 202 \% 20 \mathrm{pp} \% 20 \mathrm{v} 1.3 . \mathrm{pdf}$.

[71] Zach, K., Auer, H., Lettner, G., Mar 2012. Report summarizing the current status, role and costs of energy storage technologies. store-facilitating energy storage to allow high penetration of intermittent renewable energy. [Online], accessed 31 March 2014.

URL http://www.store-project.eu/documents/results/en_GB/report-summarizing-thecurrent-status-role-and-costs-of-energy-storage-technologies 


\section{AppendixA. Dynamic models for energy system}

The equations described below represent the behaviour of the units within the time interval of operation $t \in\left[0, t_{\text {final }}\right]$. The following convention is used in the description of the energy system model: $C$ represents the capacities of units, $\dot{E}, \dot{Q}$ and $\dot{D}$ represent electricity, heat and demand rates [MW], $S$ represents stored energy [MWh]. Subscripts $i$ and $j$ refer to the generation options (PV, WT, PT) and storage options (PHES, AA-CAES, MTS, VRFB) respectively. Superscripts gen, $s, i n$, out, el and th represent generation, storage, input, output, electrical and thermal respectively. Subscript RES refers to the renewable energy system. Other notations used are described as introduced.

\section{AppendixA.1. Generation models}

The detailed model for wind generation will be presented here. Models for the other generation technologies have been presented elsewhere [3]; only summaries will be presented here.

\section{AppendixA.1.1. Photovoltaic modelling}

Photovoltaics make use of global horizontal irradiance $\left(\mathrm{GHI}, \dot{G}^{t o t}\right.$ ), which is the total irradiance received from the sun by a surface horizontal to the ground. The electrical output of the PV system $\dot{E}_{P V}^{g e n}(t)$ is dependent on the instantaneous GHI available, the installed area of photovoltaics, and the PV and inverter efficiencies.

A solar irradiance level of $1 \mathrm{~kW} / \mathrm{m}^{2}$ (irradiance level under standard test conditions for PV modules) was employed for the calculation of the nominal PV generation capacity $C_{P V}^{g e n}$.

\section{AppendixA.1.2. Power tower modelling}

Power towers generate heat from the direct portion of solar radiation which hits the heliostat surface, called

direct normal irradiance (DNI, $\dot{G}^{D N I}$ ). Modelling the power output of the power tower $\dot{Q}_{P T}^{g e n}(t)$ requires an energy balance which takes into account the optical losses from the collector during reflection (the heliostats) and the thermal losses from the absorber.

A design irradiance of $0.95 \mathrm{~kW} / \mathrm{m}^{2}$ was employed for the calculation of the nominal power tower capacity $C_{P T}^{g e n}$.

\section{AppendixA.1.3. Wind turbine modelling}

The approach adopted for modelling the operation of wind turbines involves the division of the windspeed regime based on the conceptual power curves of wind turbines [56, 43]. Typically, the power curve is 


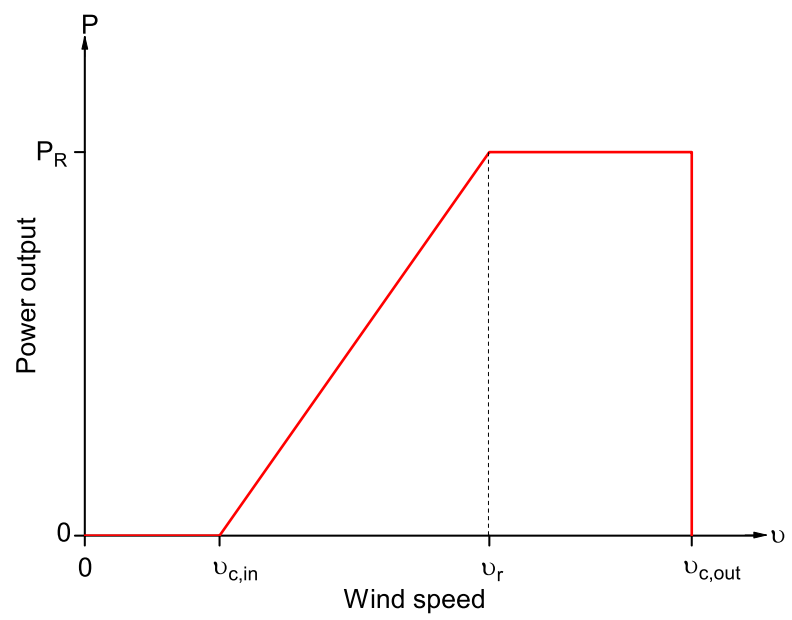

Figure A.21: Typical power curve for a wind turbine. The wind generator starts operating at $\nu_{c, i n}$, reaches its nominal power output at $\nu_{r}$, and stops running when the windspeed exceeds $\nu_{c, \text { out }}$.

subdivided into four operating regimes as shown in Figure A.21. The wind generator only starts producing power when the wind speed exceeds the minimum speed at which the turbine can operate, called the cutin speed $v_{c, i n}$. The output of the system increases linearly with windspeed until the rated windspeed $v_{r}$ is reached, beyond which the power output from the wind generator is constant. However, when the windspeed exceeds a cut-out speed $v_{c, \text { out }}$, the wind generator turbine stops running for safety reasons. The power output in each of the regions is linearly related to the rated power of the individual turbines $P_{R}$,

$$
\dot{E}_{w i n d}^{g e n}(t)=N_{T} \cdot \begin{cases}0 & \text { for } v(t)<v_{c, \text { in }} \\ P_{R}\left(\frac{v(t)-v_{c, \text { in }}}{v_{r}-v_{c, i n}}\right) & \text { for } v_{c, \text { in }} \leq v(t) \leq v_{r} \\ P_{R} & \text { for } v_{r} \leq v(t) \leq v_{c, \text { out }} \\ 0 & \text { for } v(t)>v_{c, \text { out }}\end{cases}
$$

where $N_{T}$ is the number of turbines. With this model, the power output of the turbines can be modelled if the cut-in speed, cut-out speed, rated speed and rated power are known [20].

The nominal capacity of installed wind is the product of the number of turbines and the rated power,

$$
C_{\text {wind }}^{\text {gen }}=N_{T} \cdot P_{R}
$$

The vertical profile of the windspeed at the hub height of the wind turbine is generated using the power law 
approximation [56]. It relates the windspeed at the turbine hub height to the measured windspeed as

$$
\left(\frac{v}{v_{0}}\right)=\left(\frac{H}{H_{0}}\right)^{\xi}
$$

where $\nu$ and $\nu_{0}$ are the windspeeds at heights $H$ and $H_{0}$ respectively, and $\xi$ is the friction coefficient. A value of $\xi=1 / 7$ is typically used for open terrain and well exposed sites [44, 35].

\section{AppendixA.1.4. Energy balances for generation units}

The total electrical output of the generation systems is the sum of the outputs from the wind and PV technologies,

$$
\dot{E}_{\text {total }}^{g e n}(t)=\dot{E}_{P V}^{g e n}(t)+\dot{E}_{\text {wind }}^{\text {gen }}(t)
$$

This energy can either be used to satisfy immediate demand, sent to storage or rejected to the dump load. Thus,

$$
\dot{E}_{\text {total }}^{\text {gen }}(t)=\dot{E}^{d}(t)+\dot{E}_{\text {store }}^{\text {in }}(t)+\dot{E}_{\text {dumped }}(t)
$$

where $\dot{E}^{d}(t)$ is the electricity sent directly to the plant to satisfy immediate power needs, $\dot{E}_{\text {store }}^{\text {in }}(t)$ is the energy sent to the storage systems and $\dot{E}_{\text {dumped }}(t)$ is the rejected energy.

\section{AppendixA.2. Storage models}

The electricity sent to storage from the electrical generation options is split between the three electrical storage systems,

$$
\dot{E}_{\text {store }}^{\text {in }}(t)=\dot{E}_{P H E S}^{\text {in }}(t)+\dot{E}_{A A-C A E S}^{i n}(t)+\dot{E}_{B A T}^{i n}(t)
$$

A detailed description and model for the battery system will be presented. Detailed information about the other storage technologies can be found in Amusat et al. [3], only summaries will be presented here.

\section{AppendixA.2.1. Pumped hydraulic energy storage (PHES)}

In PHES systems, excess electricity is used to pump water from a lower to an upper reservoir. During periods of high demand the process is reversed, with water flowing down from the upper reservoir used to power a turbine. The electricity is therefore stored as potential energy. The PHES system governed by the potential energy equation $\dot{E}=\dot{m} g h$, where $\dot{m}$ is the mass flow rate into or out of the upper reservoir and $h$ is the height difference between the two reservoirs. The model accounts for mechanical losses in the charging and discharging processes. 
The capacity of the PHES system is determined by the storage capacity of the upper reservoir $C_{P H E S}^{s}$ and peak output capacity of the turbine $C_{P H E S}^{\text {out }}$.

AppendixA.2.2. Advanced adiabatic compressed air energy storage (AA-CAES)

The AA-CAES system stores potential energy, in the form of high pressure air, as well as heat in a thermal energy store (TES). During charging, excess electricity is used for polytropic air compression. The heat generated during compression is collected and stored as thermal energy while the compressed air is stored separately in a cavern at near room temperature. In periods of high electricity demand, thermal energy from the TES is used in reheating of the compressed air before expansion in turbines. Energy from the TES may also be used to meet the thermal demands of the plant. The incorporation of a thermal energy store (TES) eliminates the use of fossil fuels for reheating, making it a standalone environmentally-friendly system. For this work, sensible heat storage in pre-stressed concrete is considered for thermal energy storage.

The AA-CAES model consists of a dynamic mass holdup equation for the cavern, a dynamic heat balance for the TES, and a dynamic energy accummulation equation for the AA-CAES. The model accounts for mechanical losses during compression and expansion, as well as the thermal losses from the TES.

The capacity of the AA-CAES system is defined by the peak storage capacity of the system $C_{A A-C A E S}^{s}$ and the peak electrical discharge capacity of the expander $C_{A A-C A E S}^{o u t}$.

AppendixA.2.3. Molten salt tank storage (MTS)

The MTS system consists of two cylindrical storage tanks fitted with electric heaters and maintained at fixed storage temperatures. One of the tanks, called the hot tank, stores excess thermal energy collected by the power tower. When energy is required from the MTS system, salt from this tank is used to heat up steam. The steam may then be used to supply heat or electricity (through the power block) to the plant. The other tank, called the cold tank, collects the cooled salt returning from the salt-to-steam heat exchange process. Energy is therefore stored as sensible heat.

The MTS model consists of dynamic mass and energy balances for the two storage tanks as well as equations for electriciy generation from the power block. The model accounts for thermal losses from the storage tanks to the surroundings and thermal-to-electrical energy conversion losses. The dynamic energy balances for the tanks incorporate electrical heating terms which compensate for the thermal energy losses, ensuring that the tank temperatures remains unchanged.

The capacity of the MTS system is determined by how much energy the hot tank can store $C_{M T S}^{s}$ and the peak electrical output capacity of the steam turbine $C_{M T S}^{\text {out }}$. 


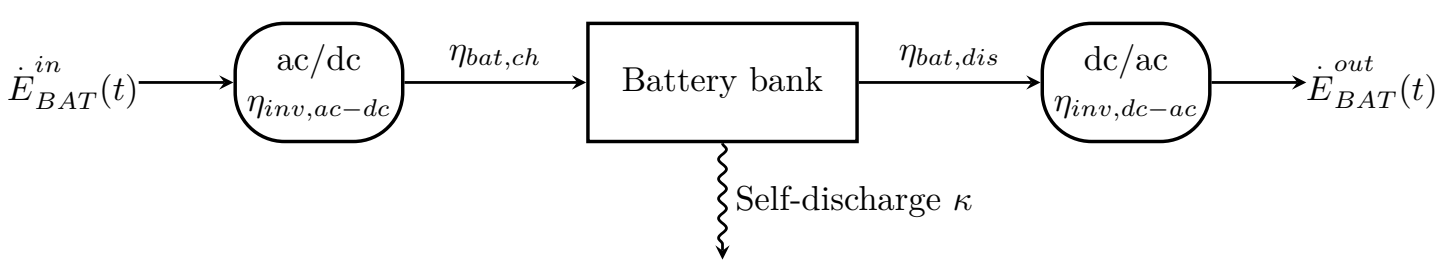

Figure A.22: Schematic of battery system showing system losses. The battery bank is made up of series and parallel connections of individual batteries.

AppendixA.2.4. Vanadium redox flow battery storage (VRFBs)

A flow battery is a type of storage battery where one or both of the reactants are liquids stored in external tanks and flow through an electrochemical cell consisting of electrodes and separator structures [66]. A crucial advantage of the redox flow battery over other battery types such as lead-acid is that it allows for the decoupling of the energy (storage capacity) and power of the battery [58, 40, 48, 69. This allows for the power and energy capacities to be scaled independently of each other, preventing oversizing and allowing greater flexibility in matching power and duration needs for specific applications [48, 69.

In Vanadium redox low batteries (VRFB), both electrolytes are made up of vanadium ions dissolved in sulphuric acid solutions, taking advantage of multiple oxidation states of vanadium [66, 58]. The operating lifetime of a typical VRFB is expected to be about 20 years [66, 40, making it one of the most durable battery technologies. Merei et al. [47] suggest that VRFB systems produce better performance than Lithium-ion and Lead-acid batteries for off-grid energy system applications. Round trip efficiencies of up to $85 \%$ have been reported [14, 40].

Figure A.22 shows a schematic of the battery system. Inverter and efficiency losses are incurred during the charge and discharge phases, while some energy is also lost from the system due to self-discharge. The self discharge rate, $\kappa$, is typically dependent on the level of charge of the battery. The rate of change of energy within a battery bank $[23,20,2]$ is given by

$$
\frac{\mathrm{d}}{\mathrm{d} t} S_{B A T}(t)=\eta_{b a t, c h} \eta_{i n v, a c-d c} \dot{E}_{B A T}^{\text {in }}(t)-\frac{\dot{E}_{B A T}^{\text {out }}(t)}{\eta_{b a t, d i s} \eta_{i n v, d c-a c}}-\kappa S_{B A T}(t)
$$

The first two terms represent the rates of energy into and out of the battery bank while the last term gives the rate of energy loss via self discharge as a function of storage level. The state of charge (SOC) of the battery at any point can be determined by dividing the storage level $S_{B A T}(t)$ by the battery capacity $C_{B A T}^{s}$. Battery banks are made up of series and parallel connections of single batteries. Given the nominal voltage $U_{\text {bat,single }}\left[\right.$ Volts] and nominal current capacity $\hat{q}_{B A T, \text { single }}^{\text {nom }}[\mathrm{Ah}]$ of a single battery, the number of batteries 
required for the bank may be calculated as:

$$
N_{b a t}=\left[\frac{\hat{q}_{B A T}^{n o m}}{\hat{q}_{B A T, \text { single }}^{\text {nom }}}\right] \cdot\left[\frac{U_{b a t}}{U_{\text {bat }, \text { single }}}\right]
$$

The first term in the square brackets gives the number of parallel battery connections required to give the desired charge storage capacity $\hat{q}_{B A T}^{n o m}[\mathrm{Ah}]$, while the second term gives the number of series connections required to obtain the desired voltage $U_{b a t}[$ Volts] [1, 7].

In addition to the dynamic model representing the battery storage level, other physical and operational constraints are required to ensure the feasibility of the designs generated and the longevity of the battery.

\section{Capacity constraints}

The energy accumulated in the battery at any pointis limited by the installed storage capacity,

$$
S_{B A T}(t) \leq C_{B A T}^{s}
$$

For a VRFB system, this is related to the size of the storage tank. Similarly, the instantaneous electrical output from the battery cannot exceed the peak output capacity,

$$
\dot{E}_{B A T}^{\text {out }}(t) \leq C_{B A T}^{\text {out }}
$$

For a VRFB system, this is related to the pump size and the area of the cell stack.

From Eqs. A.9 and A.10, the storage capacity of the battery in hours can easily be calculated:

$$
N_{s t}=\frac{C_{B A T}^{s}}{C_{B A T}^{\text {out }}}
$$

Thus, the discharge and storage capacities a battery can be calculated once $N_{b a t}$ and $N_{s t}$ are known.

Depth of discharge (DOD)

The depth of discharge $(D O D)$ is a measure of how deeply a battery has been discharged. Battery manufacturers typically provide information on the recommended lower limit the battery bank should not exceed when discharging in order to preserve battery life. Given a maximum depth of discharge $D O D_{\max }$, the minimum level of discharge of the battery will be [1]

$$
S_{B A T}^{\min }=\left(1-D O D_{\max }\right) \cdot C_{B A T}^{s}
$$

